\title{
Improving ASCAT soil moisture retrievals with an enhanced spatially-variable vegetation parameterization
}

\author{
Sebastian Hahn, Wolfgang Wagner, Senior Member, IEEE, Susan Steele-Dunne, \\ Mariette Vreugdenhil and Thomas Melzer
}

\begin{abstract}
This study investigates the performance of the TU Wien soil moisture retrieval algorithm (TUW-SMR) by adapting the strength of the vegetation correction. The semiempirical change detection method TUW-SMR exploits the multi-angle backscatter observations from spaceborne fan-beam scatterometer systems in order to derive surface soil moisture information expressed in degree of saturation. The vegetation parameterization of TUW-SMR is controlled by the dry and wet cross-over angles that are used to determine the dry and wet backscatter reference. Backscatter observations from the Advanced Scatterometer (ASCAT) are used to produce four soil moisture data sets based on different dry and wet crossover angles describing: (i) a static respectively no vegetation correction, (ii) the currently used seasonal vegetation correction (iii) a stronger seasonal vegetation correction and (iv) a spatiallyvariable seasonal vegetation correction with the stronger vegetation correction over vegetated areas and no vegetation correction over bare land. All four ASCAT soil moisture data sets are evaluated against soil moisture estimates from GLDAS-2.1 Noah land surface model and the ESA CCI Passive v04.5 soil moisture product using the triple collocation method and a traditional correlation analysis. The results show that the spatially-variable vegetation correction overall improves soil moisture estimates in both more densely vegetated areas, e.g. in large parts of North America and Europe, and more sparsely-vegetated, e.g. Western Africa. Nonetheless, the experiment also provides insight into challenging retrieval conditions where the TUW-SMR fails to take all relevant backscatter processes into account, e.g. wetlands and bare soils with sub-surface scattering.
\end{abstract}

Index Terms-Performance evaluation, Radar remote sensing, Radar cross-sections, Soil moisture.

\section{INTRODUCTION}

$\mathbf{T}$ HE topic of microwave remote sensing of soil moisture has been studied extensively [1]-[4]. Microwaves exhibit a strong dependence on the soil dielectric properties, which are largely controlled by the water content in the soil. In addition, microwaves benefit from the fact that they are hardly affected by clouds and independent of solar illumination. Therefore, microwaves have proven to be a useful tool to measure soil moisture changes over land.

S. Hahn, W. Wagner, M. Vreugdenhil, T. Melzer are with the Department of Geodesy and Geoinformation, Vienna University of Technology (TU Wien), Vienna, Austria (e-mail: sebastian.hahn@geo.tuwien.ac.at; wolfgang.wagner@geo.tuwien.ac.at; mariette.vreugdenhil@geo.tuwien.ac.at; thomas.melzer@geo.tuwien.ac.at).

S. Steele-Dunne is with the Faculty of Civil Engineering and Geosciences, Delft University of Technology, 2628CN Delft, The Netherlands (e-mail s.c.steele-dunne @tudelft.nl).

Manuscript received June 1, 2020; revised June 1, 2020.
Numerous satellite soil moisture products have been developed and published based on active and passive microwave instruments [5]-[11]. Furthermore, effort has been directed towards merging active and passive microwave satellite soil moisture products in the framework of ESA's Climate Change Initiative (CCI) [12], [13]. By harnessing the assets of active and passive microwave instruments, it is possible to overcome the limitations of one technique by another.

However, vegetation cover effects are still a challenge when deriving surface soil moisture information from active and passive microwave instruments. When the soil surface is covered by vegetation, part of the microwave radiation is absorbed and scattered. A mix of surface, volume and multiple scattering is reducing the signal sensitivity to soil moisture [14], [15]. Various approaches have been investigated to account for vegetation effects e.g. using optical vegetation indices (e.g. Normalized Difference Vegetation Index (NDVI), Leaf Area Index (LAI)) [16], [17], directly estimating vegetation parameters from microwave measurements (e.g. Vegetation Optical Depth (VOD), Radar Vegetation Index (RVI), polarization ratio) [4], [9], [18], or exploiting multi-angle backscatter observations [10], [19]. The TU Wien soil moisture retrieval algorithm (TUW-SMR) belongs to the last category, since it utilizes the multi-angle measurement capabilities of spaceborne fan-beam scatterometer to account for vegetation during the retrieval of surface soil moisture [20].

TUW-SMR was originally developed for the C-band scatterometer instruments on-board ERS-1 and ERS-2 [10] and later applied to the Advanced Scatterometer (ASCAT) onboard the series of Metop satellites [11], [21]. The vegetation parameterization of TUW-SMR exploits the incidence angle dependence of backscatter, relating it to vegetation and soilvegetation interaction effects [22], [23]. It is based on the assumption that a change in soil moisture equally affects the backscatter intensity (expressed in $\mathrm{dB}$ ) across the incidence angle range between $20^{\circ}-60^{\circ}$, whereas vegetation phenology results in more complex variations in the incidence angle dependence of backscatter. Applying this abstraction to specific soil and vegetation states eventually leads to intersections at certain incidence angles. The so-called cross-over angle concept utilizes this behavior by defining two distinct incidence angle at which the backscatter signal is independent from vegetation changes in case of a dry and wet (saturated) soil. Based on empirical observations from previous studies using ERS-1 and ERS-2 scatterometer data, the dry and 


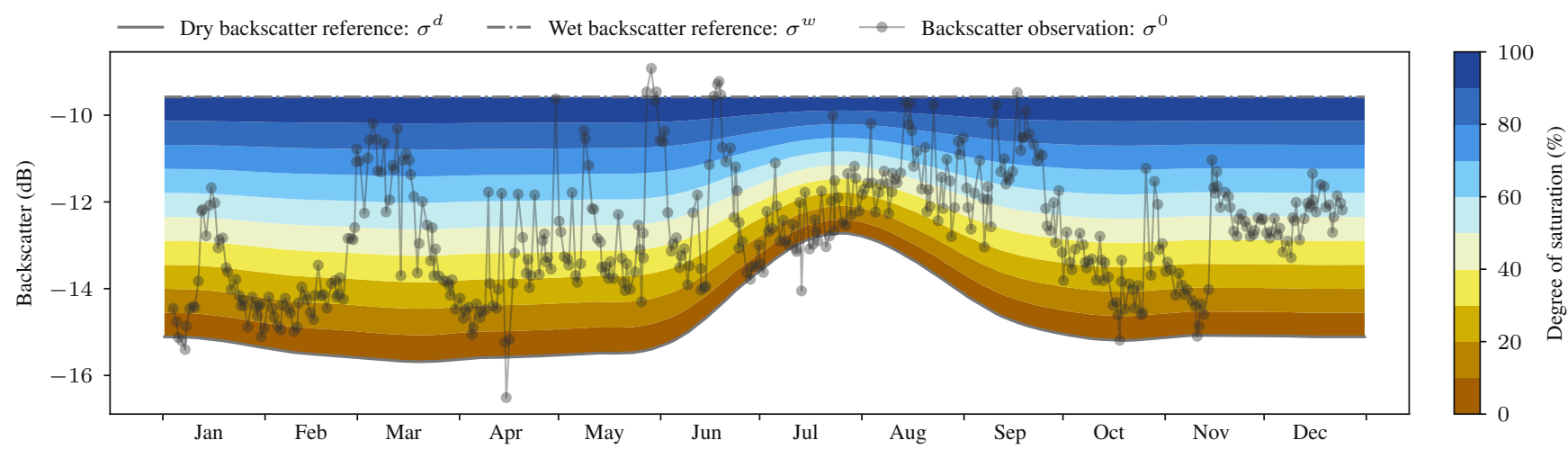

Fig. 1. The TU Wien soil moisture retrieval algorithm is a physically-based semi-empirical change detection method. Backscatter observations $\sigma^{0}$ are normalized to a common reference incidence angle $\left(\theta_{r}=40^{\circ}\right)$ and scaled between a dry and wet backscatter reference $\left(\sigma^{d}\right.$, $\left.\sigma^{w}\right)$. Soil moisture is expressed in degree of saturation ranging between 0 (dry soil conditions) and $100 \%$ (saturated soil condition).

wet cross-over angles are set to $\theta_{d}=25^{\circ}$ and $\theta_{w}=40^{\circ}$ globally [10], [22], [24]. The choice of the cross-over angles is important because they directly influence the amplitude of the dynamic vegetation correction and ultimately determine the signal sensitivity to soil moisture (i.e. the distance between the dry and wet backscatter reference).

Recent research has shown that in some areas seasonal vegetation biases are evident [25], [26]. The selection of $\theta_{d}$ and $\theta_{w}$ has not been changed since the initial development of TUWSMR and no dedicated experiments have so far been conducted changing them on a global scale. A first study adapting the vegetation parameterization to regional conditions indicated a clear benefit of using a stronger vegetation correction in an agricultural area in Lower Austria [27].

In the present study we evaluate the performance of TUWSMR globally using different pairs of dry and wet cross-over angles:

1) $\theta_{d}=40^{\circ}$ and $\theta_{w}=40^{\circ}$ which switches off the vegetation correction over bare land surface areas respectively assumes that the scattering behaviour of vegetation is stable over the year.

2) $\theta_{d}=25^{\circ}$ and $\theta_{w}=40^{\circ}$ representing the current seasonal vegetation correction.

3) $\theta_{d}=10^{\circ}$ and $\theta_{w}=30^{\circ}$ representing the stronger vegetation parameterization successfully tested by [27] over temperate climates.

4) a spatially-variable choice of cross-over angles derived from a Vegetation Continuous Fields (VCF) data set to tune the vegetation correction from no vegetation correction over bare land surfaces to the stronger vegetation parameterization over vegetated areas.

Hence, four different ASCAT surface soil moisture data records are computed and evaluated using soil moisture information from the Global Land Data Assimilation System (GLDAS) Noah v2.1 [28] and the ESA CCI Passive soil moisture data set v4.5 [29] for the time period January 2007 until December 2018. The main performance metrics computed in this study are the Pearson Correlation Coefficient and the estimated error variance expressed as Signal-to-Noise Ratio (SNR) derived using Triple Collocation (TC) [30], [31].

\section{BACKGROUND}

\section{A. TU Wien soil moisture retrieval algorithm}

The TU Wien soil moisture retrieval algorithm (TUWSMR) represents a change detection method developed for scatterometer instruments in 1999 [10], [22], [24]. Stepwise improvements have been developed in the past years, such as correcting azimuthal anisotropy [32], supporting Metop ASCAT [21] and error characterization [33]. Figure 1 illustrates the final step in the change detection method and Equation 1 its mathematical expression. Backscatter observations $\left(\sigma^{0}\right)$ normalized to a common reference incidence angle $\left(\theta_{r}=40^{\circ}\right)$ are scaled between a dry and wet backscatter reference $\left(\sigma^{d}\right.$, $\left.\sigma^{w}\right)$, resulting in relative surface soil moisture information $\left(m_{s}\right)$ expressed in degree of saturation. The surface soil moisture values range between 0 (dry soil conditions) and $100 \%$ (saturated soil conditions) and any $\sigma^{0}$ observation outside the dry/wet backscatter reference are either corrected to $0 / 100 \%$ or rejected as an extreme outlier.

$$
m_{s}(t)=\frac{\sigma^{0}(t)-\sigma^{d}(t)}{\sigma^{w}(t)-\sigma^{d}(t)} \cdot 100 \quad[\%]
$$

The physical basis of TUW-SMR can be attributed to the strong linear relationship between C-band backscatter and soil water content in the top soil layer $(1-2 \mathrm{~cm})$ [11]. Despite the lack of a direct parameterization of common soil surface properties (e.g. surface roughness, vegetation, land cover) which are usually part of semi-empirical or theoretical backscatter models, TUW-SMR is grounded on physical principles and the following basic assumptions [10]:

1) The relationship between the backscatter coefficient $\sigma^{0}$ expressed in decibels $(\mathrm{dB})$ and the surface soil moisture content is linear.

2) Surface roughness and land cover are temporally stable at a spatial resolution of $25 / 50 \mathrm{~km}$.

3) The incidence angle dependence of $\sigma^{0}$ characterizes soil roughness conditions and land cover dynamics, but is not affected by changes in the surface soil moisture content.

4) The effect of vegetation on $\sigma^{0}$ changes on a seasonal scale without inter-annual variations. 
One advantage of this method is that model parameterization is possible without an iterative adjustment, which is normally necessary for more complex backscatter models. Furthermore, the simple mathematical description allows for a straightforward application of error propagation analysis to estimate a retrieval error of the final surface soil moisture estimate [23].

TUW-SMR model parameters can either be predefined globally or estimated for each individual location on the land surface. Thus, model parameters can be spatially and temporally constant (i.e. $\theta_{r}=40^{\circ}, \theta_{d}=25^{\circ}, \theta_{w}=40^{\circ}$ ) or change temporally and geographically (i.e. $\sigma^{\prime}, \sigma^{\prime \prime}, \sigma^{d}, \sigma^{w}$ ). The estimation of the unknown model parameters is typically done in the time domain and computationally expensive. Longterm backscatter time series ( $>2-4$ years) are needed for each location in order to compute robust results.

\section{B. The cross-over angle concept}

TUW-SMR assumes that distinct cross-over angles exist at which the backscatter signal is independent from vegetation phenology. Figure 2 depicts this concept showing backscatter curves for four special cases. Two distinct intersections can be registered, the so-called dry and wet cross-over angles $\left(\theta_{d}\right.$, $\left.\theta_{w}\right)$, where backscatter intensity is no longer dependent on the vegetation state. The selection of $\theta_{d}=25^{\circ}$ and $\theta_{w}=40^{\circ}$ is based on empirical observations and analysis from previous studies [10], [22], [24].

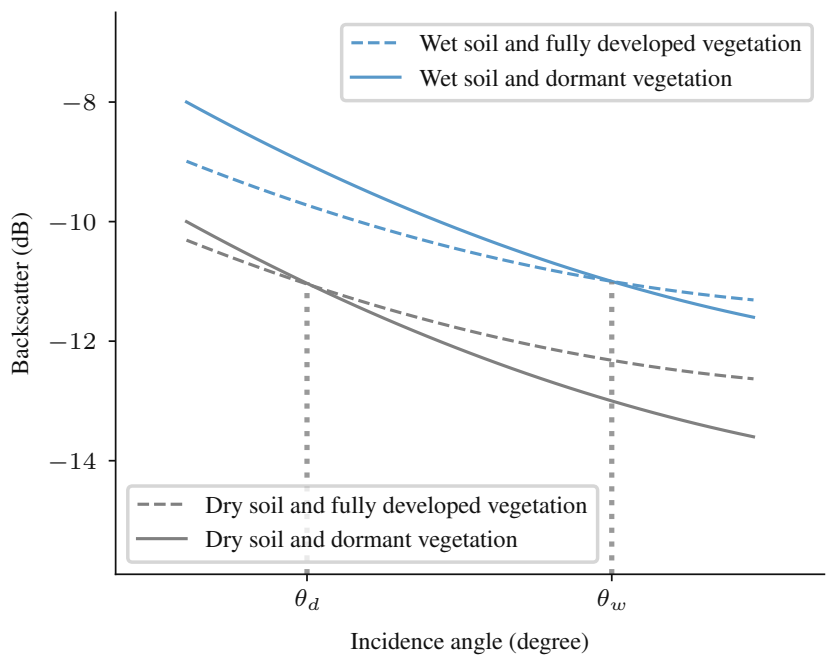

Fig. 2. Illustration of the cross-over angle concept after [24]. Two distinct intersections can be registered for dry and wet soil conditions, which are called dry and wet cross-over angles $\left(\theta_{d}, \theta_{w}\right)$.

The dry and wet cross-over angles are important parameters because the dry and wet backscatter references are computed at these incidence angles. A second-order Taylor polynomial is used to describe the incidence angle dependency of backscatter (see Equation 2). The so-called slope $\sigma^{\prime}$ and curvature $\sigma^{\prime \prime}$ are used to normalize backscatter observed at arbitrary incidence angles $\left(\sigma_{\theta}^{0}\right)$ to a common reference incidence angle $\left(\theta_{r}=40^{\circ}\right)$. $\sigma^{\prime}$ and $\sigma^{\prime \prime}$ represent the first and second derivative of backscatter with respect to the incidence angle, which are estimated for each location independently and change temporally [34]. $\sigma^{0}(t)=\sigma_{\theta}^{0}(t)-\sigma^{\prime}(t) \cdot\left(\theta-\theta_{r}\right)-\frac{1}{2} \cdot \sigma^{\prime \prime}(t) \cdot\left(\theta-\theta_{r}\right)^{2}$

Rearranging Equation 2 allows us to convert $\sigma^{0}$ from the reference incidence angle $\theta_{r}$ to $\theta_{d}$ and $\theta_{w}$, respectively:

$\sigma_{d}^{0}(t)=\sigma^{0}(t)+\sigma^{\prime}(t) \cdot\left(\theta_{d}-\theta_{r}\right)+\frac{1}{2} \cdot \sigma^{\prime \prime}(t) \cdot\left(\theta_{d}-\theta_{r}\right)^{2}$

$\sigma_{w}^{0}(t)=\sigma^{0}(t)+\sigma^{\prime}(t) \cdot\left(\theta_{w}-\theta_{r}\right)+\frac{1}{2} \cdot \sigma^{\prime \prime}(t) \cdot\left(\theta_{w}-\theta_{r}\right)^{2}$

The backscatter time series at the cross-over angle $\left(\sigma_{d}^{0}, \sigma_{w}^{0}\right)$ are used to determine the dry and wet backscatter reference from the extreme lowest and highest backscatter values. The selection of the extreme backscatter observations is based on a confidence interval determined by the noise distribution of the backscatter at the respective cross-over angle [23]. The average of the two selected backscatter subsamples represents the dry and wet backscatter reference at the dry and wet crossover angles $\left(C_{d}^{0}, C_{w}^{0}\right)$. A final transformation of $C_{d}^{0}$ and $C_{w}^{0}$ is needed in order to convert the backscatter values from the cross-over angles back to $\theta_{r}=40^{\circ}$ :

$$
\begin{aligned}
& \sigma^{d}(t)=C_{d}^{0}-\sigma^{\prime}(t) \cdot\left(\theta_{d}-\theta_{r}\right)-\frac{1}{2} \cdot \sigma^{\prime \prime}(t) \cdot\left(\theta_{d}-\theta_{r}\right)^{2} \\
& \sigma^{w}(t)=C_{w}^{0}-\sigma^{\prime}(t) \cdot\left(\theta_{w}-\theta_{r}\right)-\frac{1}{2} \cdot \sigma^{\prime \prime}(t) \cdot\left(\theta_{w}-\theta_{r}\right)^{2}
\end{aligned}
$$

It is worth noting that $C_{d}^{0}$ and $C_{w}^{0}$ are both constant values (at the respective cross-over angle), but as a result of the final transformation to $\theta_{r}, \sigma^{\prime}$ and $\sigma^{\prime \prime}$ impose their temporal signature on $\sigma^{d}$ and $\sigma^{w}$. Technically, this is only the case for $\sigma^{d}$ for the current settings, because $\theta_{r}=\theta_{w}$.

Figure 3 shows an example of $\sigma^{d}$ and $\sigma^{w}$ determined at different cross-over angles and transformed back to $\theta_{r}$. It can be seen that the selection of the cross-over angle controls the strength of the temporal characteristics. A lower cross-over angle enhances the temporal signature coming from $\sigma^{\prime}$ and $\sigma^{\prime \prime}$. In the extreme case that the cross-over angle is equal to the reference incidence angle, no transformation is necessary and the reference is constant. The distance between $\sigma^{d}$ and $\sigma^{w}$ determines the backscatter signal sensitivity to changes in soil moisture. Naturally, with increasing vegetation coverage, backscatter sensitivity to changes in soil moisture is decreasing due to attenuation effects. A typical variable in microwave remote sensing describing vegetation attenuation properties is the Vegetation Optical Depth (VOD). In fact, [20] developed a method deriving VOD by ingesting $\sigma^{d}$ and $\sigma^{w}$ into a Water Cloud Model (WCM) [14], [35], which compared well in temperate and continental climates to VOD derived from passive microwave observations. Hence, the selection of $\theta_{d}$ and $\theta_{w}$ determines the temporal development of $\sigma^{d}$ and $\sigma^{w}$, which, ultimately, can be interpreted as changes in VOD. 


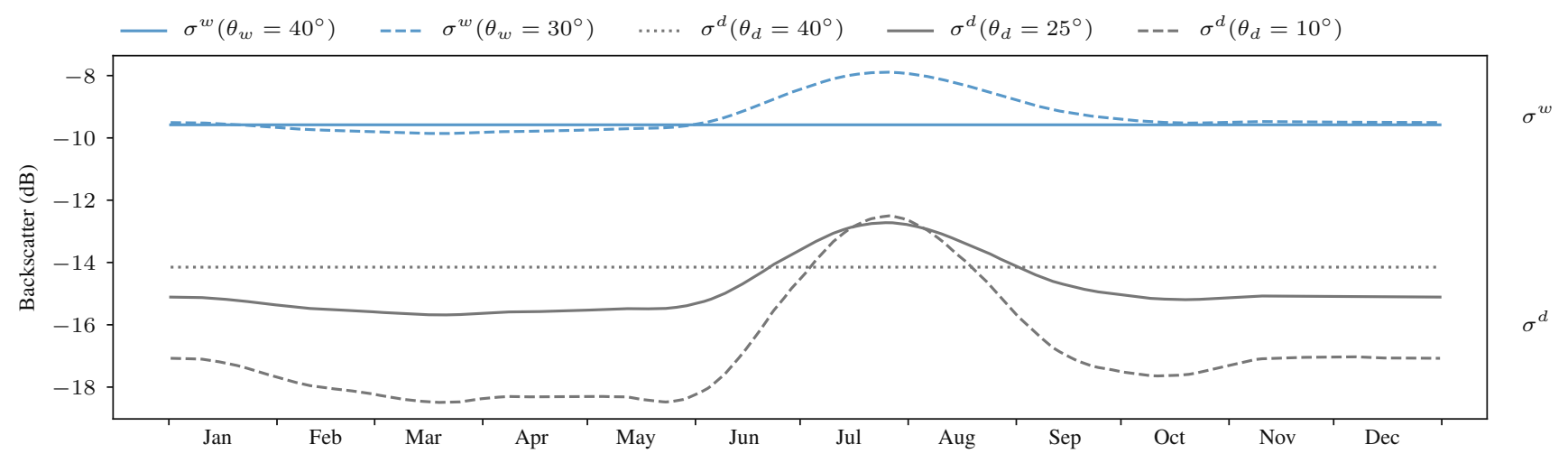

Fig. 3. Examples of different dry $\left(\sigma^{d}\right)$ and wet $\left(\sigma^{w}\right)$ backscatter references at $\theta_{r}=40^{\circ}$ derived using different dry and wet cross-over angles $\left(\theta_{d}=\right.$ $\left.\left\{10^{\circ}, 25^{\circ}, 40^{\circ}\right\}, \theta_{w}=\left\{30^{\circ}, 40^{\circ}\right\}\right)$.

\section{DATA SETS}

\section{A. Metop ASCAT backscatter}

The Advanced Scatterometer (ASCAT) on-board the series of Metop satellites is an active C-band $(5.255 \mathrm{GHz})$ radar using six vertically polarized fan-beam antennas. From around $800 \mathrm{~km}$ altitude ASCAT transmits well characterized pulses of microwave energy towards the Earth's surface and measures the reflected energy expressed in terms of the Normalized Radar Cross Section (NRCS), also known as backscatter coefficient $\sigma^{0}$ [36]. ASCAT represents a follow-on scatterometer for the Active Microwave Instruments (AMI) on-board ERS-1 and ERS-2 [37] and has proven to be a stable and well calibrated instrument [38], [39]. Two main Level 1b backscatter products are generated by spatially averaging the geolocated full resolution backscatter measurements in order to obtain $\sigma^{0}$ triplets from the Fore, Mid and Aft beam resampled on a regular orbit grid: Sigma Zero Operational (SZO) with a spatial resolution of about $50 \mathrm{~km}$, sampled on 21 nodes across each swath, with a spacing of approximately $25 \mathrm{~km}$ between nodes and successive rows of nodes and Sigma Zero Research (SZR) with a spatial resolution of $25-34 \mathrm{~km}$, sampled on 41 nodes across each swath, with a spacing of approximately $12.5 \mathrm{~km}$ [39]. The latter uses a dynamic filter size in order to maintain a similar radiometric resolution at the cost of altering the spatial resolution in the cross-track direction.

At the moment, all three Metop satellites share the same sun-synchronous orbit and each carries an ASCAT instrument. The series of Metop satellites were launched 6 years apart, starting with Metop-A in October 2006, Metop-B in September 2012 and Metop-C in November 2018. In order to extend the lifetime of Metop-A, the spacecraft will be directed into a drifting orbit shifting the satellites Local Time of the Descending Node (LTDN) from 9:30 a.m. (nominal) to 7:30 a.m. by April 2022. Afterwards, Metop-A will be de-orbited into a 25 years re-entry orbit [40].

In this study we used Metop-A and Metop-B Level 1b SZR products, which have been downloaded from the EUMETSAT data centre ${ }^{1}$. In case of the Metop-A, a Fundamental Climate Data Record (FCDR) exists covering January 2007

\footnotetext{
${ }^{1}$ https://eoportal.eumetsat.int/
}

to March 2014, which has been extended with the Metop-A Level $1 \mathrm{~b}$ SZR product from the operational ground segment until December 2018. Currently no FCDR is available for Metop-B, therefore the Metop-B Level 1b SZR product from the operational ground segment has been downloaded for the period January 2013 until December 2018.

\section{B. GLDAS-2.1 Noah soil moisture}

The Global Land Data Assimilation System (GLDAS) is a global, high-resolution, offline (uncoupled to the atmosphere) terrestrial modeling system that ingests satellite- and groundbased observations and has been developed jointly by $\mathrm{Na}$ tional Aeronautics and Space Administration (NASA) Goddard Space Flight Center (GSFC) and the National Oceanic and Atmospheric Administration (NOAA) National Centers for Environmental Prediction (NCEP) [28], [41]. In this paper we used the GLDAS-2.1 Noah 0.25 degree 3-hourly product, which has been simulated with the Noah Model 3.3 in Land Information System (LIS) version 7 [42]. It contains 36 land surface fields from January 2000 until present. The data were downloaded from the NASA Goddard Earth Sciences Data and Information Services Center (GES DISC) for the period January 2007 until December $2018^{2}$.

The Noah model incorporates soil-vegetation-atmosphere transfer schemes (SVATS), with vegetation properties controlling fluxes and storages of energy and water at the land surface. GLDAS makes use of a vegetation classification map and also utilizes satellite derived leaf area index (LAI) from both the AVHRR and MODIS sensors (Rodell et al 2004). Therefore, unlike active and passive microwave-based soil moisture products (where vegetation is part of the received signal and needs to be accounted for), the seasonal cycle of GLDAS soil moisture is indirectly affected by vegetation controlled by SVATS.

GLDAS-2.1 Noah has a total of four different layers representing soil moisture: $0-10 \mathrm{~cm}, 10-40 \mathrm{~cm}, 40-100 \mathrm{~cm}$ and $100-200 \mathrm{~cm}^{2}$ expressed in $\mathrm{kg} \mathrm{m}^{-2}$. In this study we used soil moisture information from the first soil layer $0-10 \mathrm{~cm}$, as well as snow water equivalent and soil temperature $0-10 \mathrm{~cm}$ to mask potentially invalid remote sensing soil moisture observations.

\footnotetext{
${ }^{2}$ https://disc.gsfc.nasa.gov/
} 


\section{ESA CCI Passive soil moisture}

In 2009, the European Space Agency (ESA) started the Climate Change Initiative (CCI) in response to the need for climate-monitoring satellite data. Soil moisture has been recognized as an Essential Climate Variable (ECV) and became part of the ESA CCI program in 2012. The ESA CCI soil moisture project ${ }^{3}$ combines multiple active and passive microwave soil moisture products generating three harmonized climate data records: Active, Passive and Merged. In this study we used the ESA CCI Passive soil moisture product v04.5 expressing surface soil moisture in $\mathrm{m}^{3} \mathrm{~m}^{-3}$ covering the period from 1978-11-01 until 2018-12-31 [29], [43], [44].

The main data sources for the ESA CCI Passive product v04.5 for the period under investigation (2007-2018) are based on AMSR-E, WindSat, AMSR2 and SMOS. All satellite data are processed with the so-called Land Parameter Retrieval Model (LPRM) [45]. LPRM is a zero order radiative transfer model and makes use of the Microwave Polarization Difference Index (MPDI) to calculate vegetation optical depth, which is used to parameterize the attenuation of the signal by the vegetation [46].

\section{Vegetation Continuous Fields - VCF5KYR}

The NASA Making Earth System Data Records for Use in Research Environments (MEaSUREs) ${ }^{4}$ Vegetation Continuous Fields (VCF) Version 1 data product (VCF5KYR) provides global fractional vegetation cover at $0.05^{\circ}$ spatial resolution at yearly intervals from 1982 to 2016 [47]. The VCF5KYR product is derived from a bagged linear model algorithm using observations from the Advanced Very High Resolution Radiometer (AVHRR) Long Term Data Record Version 4 (LTDR V4). The three bands included in VCF5KYR are: percent of tree cover $(t c)$, non-tree vegetation $(v)$ and bare ground $(b g)$.

In this study we utilized the VCF5KYR 2016 data to estimate the dry (Equation 7) and wet (Equation 8) crossover angle. The three bands are used as weights assuming that no vegetation correction is required in case of bare ground $\left(\theta_{d}=\theta_{w}=40^{\circ}\right)$, while tree and non-tree vegetated surfaces tend to have lower cross-over angle $\left(\theta_{d}=10^{\circ}, \theta_{w}=30^{\circ}\right)$.

$$
\begin{aligned}
& \theta_{d}=10 \cdot v+10 \cdot t c+40 \cdot b g \\
& \theta_{w}=30 \cdot v+30 \cdot t c+40 \cdot b g
\end{aligned}
$$

The global maps shown in Figure 4 illustrate the spatial distribution of $\theta_{d}$ and $\theta_{w}$ derived from the VCF5KYR 2016 data set using Equation 7 and 8.

\section{E. Köppen-Geiger climate classification}

The Köppen-Geiger climate classification ${ }^{5}$ realized by [48] is sampled on a regular $0.5^{\circ}$ lat/lon grid and defines 30 climate

\footnotetext{
${ }^{3}$ http://www.esa-soilmoisture-cci.org/

${ }^{4}$ https://earthdata.nasa.gov/community/community-data-systemprograms/measures-projects

${ }^{5} \mathrm{https}$ //people.eng.unimelb.edu.au/mpeel/koppen.html
}

(a)

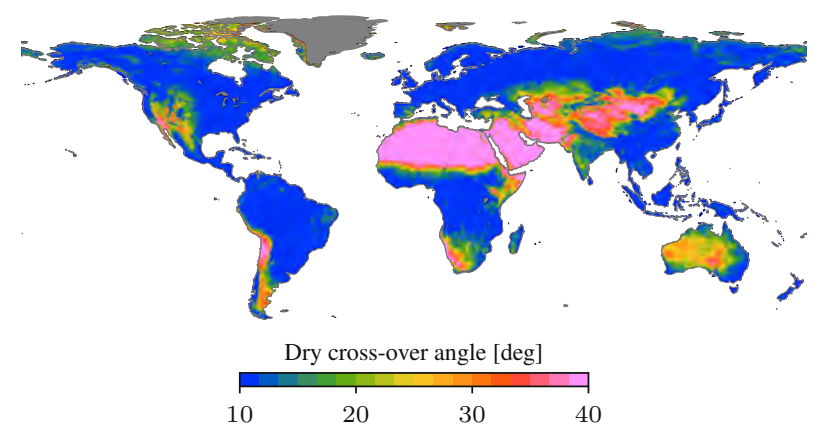

(b)

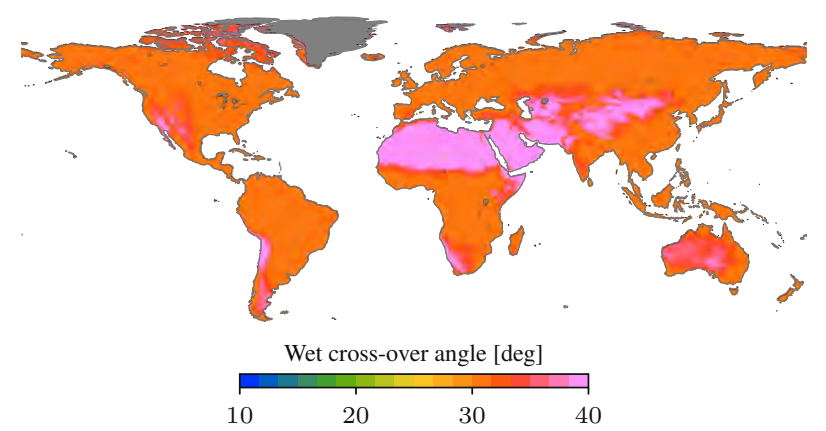

(c)

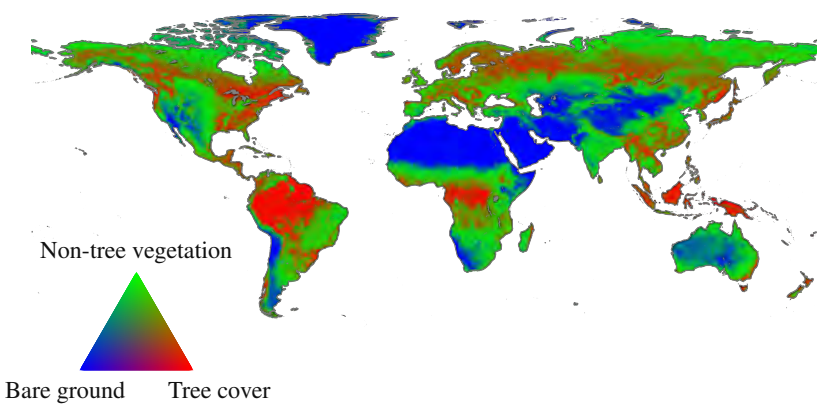

Fig. 4. Dry (a) and wet (b) cross-over angles derived from the VCF5KYR 2016 data $\operatorname{set}(\mathrm{c})$.

classes (see Table I). In this study we used the KöppenGeiger classification to group validation results by climate type around the world.

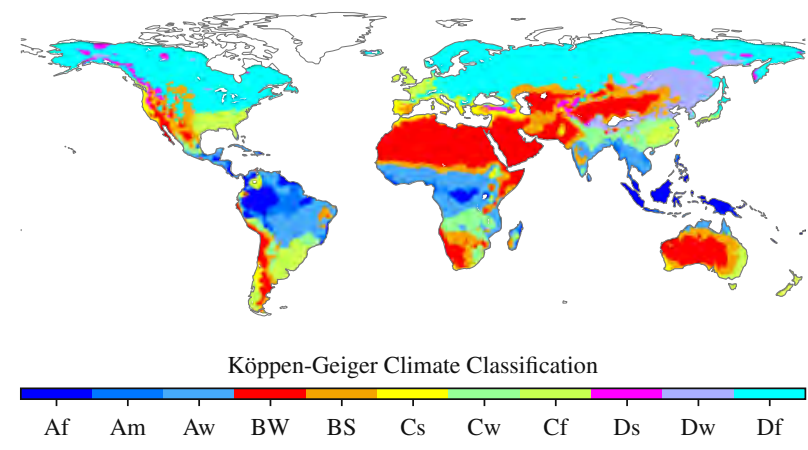

Fig. 5. Köppen Geiger Climate classification map. 
TABLE I

KÖPPEN-GEIGER CLIMATE SYMBOLS AFTER [48]

\begin{tabular}{|c|c|c|c|}
\hline 1 st & 2nd & 3 rd & Description \\
\hline \multirow[t]{3}{*}{ A } & & & Tropical \\
\hline & $\mathrm{f}$ & & - Rainforest \\
\hline & $\mathrm{m}$ & & - Savannah \\
\hline \multirow[t]{5}{*}{ B } & & & Arid \\
\hline & W & & - Desert \\
\hline & $\mathrm{S}$ & & - Steppe \\
\hline & & $\mathrm{h}$ & - Hot \\
\hline & & $\mathrm{k}$ & - Cold \\
\hline \multirow[t]{7}{*}{$\mathrm{C}$} & & & Temperate \\
\hline & $\mathrm{s}$ & & - Dry Summer \\
\hline & $\mathrm{w}$ & & - Dry Winter \\
\hline & f & & - Without dry season \\
\hline & & $\mathrm{a}$ & - Hot Summer \\
\hline & & b & - Warm Summer \\
\hline & & c & - Cold Summer \\
\hline \multirow[t]{8}{*}{ D } & & & Cold \\
\hline & $\mathrm{s}$ & & - Dry Summer \\
\hline & $\mathrm{w}$ & & - Dry Winter \\
\hline & f & & - Without dry season \\
\hline & & $\mathrm{a}$ & - Hot Summer \\
\hline & & b & - Warm Summer \\
\hline & & $\mathrm{c}$ & - Cold Summer \\
\hline & & $\mathrm{d}$ & - Very Cold Winter \\
\hline \multirow[t]{3}{*}{ E } & & & Polar \\
\hline & $\mathrm{T}$ & & - Tundra \\
\hline & $\mathrm{F}$ & & - Frost \\
\hline
\end{tabular}

\section{F. ESA CCI Land Cover}

The ESA CCI Land Cover project provides annual land cover maps (1992-2015) at $300 \mathrm{~m}$ spatial resolution [49]. The land cover map 2015 v2.0.7 was aggregated to $12.5 \mathrm{~km}$ collecting the fractional area of each land cover class and its majority class. The data set was used to group validation results by land cover type. Subclasses are merged into their respective main class (see Table II).

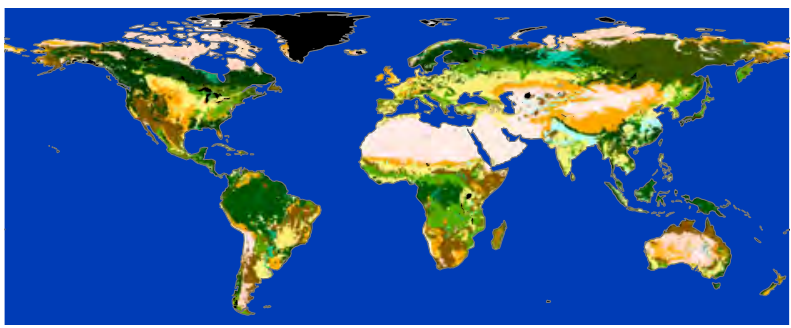

ESA CCI Landcover

$0 \begin{array}{lllllllllll}0 & 10 & 20 & 30 & 40 & 50 & 60 & 70 & 80 & 90 & 100110120130150160180190200\end{array}$

Fig. 6. ESA CCI land cover map 2015 (v2.0.7).

\section{Methods}

TUW-SMR was applied to Metop-A and Metop-B ASCAT backscatter observations, which were resampled from their original orbit swath geometry to a fixed Earth grid beforehand. This pre-processing step is necessary because backscatter
TABLE II

ESA CCI LAND COVER CLASS DESCRIPTIONS.

\begin{tabular}{|c|c|}
\hline Identifier & Description \\
\hline $10,11,12$ & Cropland, rainfed \\
\hline 20 & Cropland, irrigated or post-flooding \\
\hline 30 & $\begin{array}{l}\text { Mosaic cropland }(>50 \%) \text { / natural vegetation } \\
\text { (tree, shrub, herbaceous cover) }\end{array}$ \\
\hline 40 & $\begin{array}{l}\text { Mosaic natural vegetation (tree, shrub, } \\
\text { herbaceous cover })(>50 \%) / \text { mosaic cropland }\end{array}$ \\
\hline 50 & $\begin{array}{l}\text { Tree cover, broadleaved, evergreen, } \\
\text { closed to open }(>15 \%)\end{array}$ \\
\hline $60,61,62$ & $\begin{array}{l}\text { Tree cover, broadleaved, deciduous, } \\
\text { closed to open }(>15 \%)\end{array}$ \\
\hline $70,71,72$ & $\begin{array}{l}\text { Tree cover, needleleaved, evergreen, } \\
\text { closed to open }(>15 \%)\end{array}$ \\
\hline $80,81,82$ & $\begin{array}{l}\text { Tree cover, needleleaved, deciduous, } \\
\text { closed to open }(>15 \%)\end{array}$ \\
\hline 90 & Tree cover, mixed leaf type \\
\hline 100 & $\begin{array}{l}\text { Mosaic tree and shrub }(>50 \%) \text {, } \\
\text { herbaceous cover }(<50 \%)\end{array}$ \\
\hline 110 & $\begin{array}{l}\text { Mosaic herbaceous cover }(>50 \%) \text {, } \\
\text { tree and shrub }(<50 \%)\end{array}$ \\
\hline $120,121,122$ & Shrubland \\
\hline 130 & Grassland \\
\hline 140 & Lichens and mosses \\
\hline $150,151,152,153$ & Sparse vegetation (tree, shrub, herbaceous cover) \\
\hline 160,170 & Tree cover, flooded, saline, fresh or brakish water \\
\hline 180 & $\begin{array}{l}\text { Shrub or herbaceous cover, flooded, } \\
\text { fresh/saline/brakish water }\end{array}$ \\
\hline $200,201,202$ & Bare areas \\
\hline
\end{tabular}

TABLE III

ASCAT SOIL MOISTURE DATA SETS.

\begin{tabular}{l|l|l|l} 
Name & $\theta_{d}\left[^{\circ}\right]$ & $\theta_{w}\left[^{\circ}\right]$ & Description \\
\hline ASCAT SM-10/30 & 10 & 30 & strong vegetation correction \\
ASCAT SM-25/40 & 25 & 40 & present standard settings \\
ASCAT SM-40/40 & 40 & 40 & only static vegetation correction \\
ASCAT SM-Dyn & $10-40$ & $30-40$ & variable cross-over angles
\end{tabular}

observations in time series format are needed by TUW-SMR. The so-called WARP5 grid was used as a spatial reference with a global equidistant sampling of $12.5 \mathrm{~km}$ [23]. A search radius of $34 \mathrm{~km}$ was centered around each WARP5 land grid point selecting original orbit swath backscatter observations inside, which were subsequently weighted and averaged using a Hamming window function. In this way, a backscatter time series was generated incrementally and used as input for TUW-SMR. TUW-SMR was applied four times, with each run generating a surface soil moisture data set based on a different set of cross-over angles (see Table III).

The ASCAT surface soil moisture data sets (ASCAT SM10/30, ASCAT SM-25/40, ASCAT SM-40/40 and ASCAT SM-Dyn) were validated against GLDAS-2.1 Noah and CCI Passive soil moisture computing the Pearson correlation coefficient (R) and by applying Triple Collocation (TC). TC is a method to study error characteristics from three spatially and temporally collocated data sets [30]. The mean squared random error of all three data sets are estimated individually by cross-multiplying differences between them. The computed 
(a)

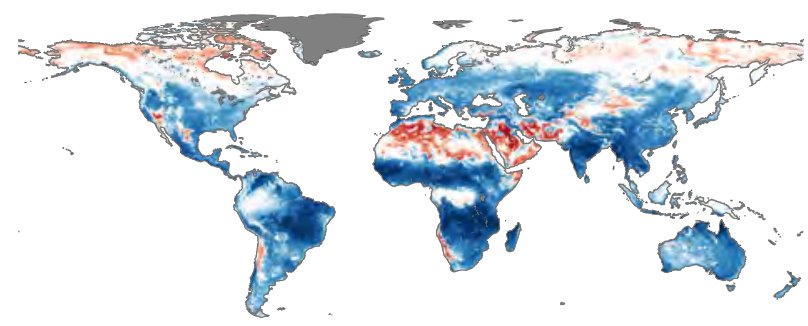

ASCAT SM-25/40 vs GLDAS-2.1 Noah SM: R [-]

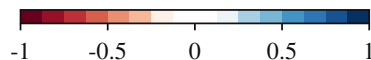

(b)

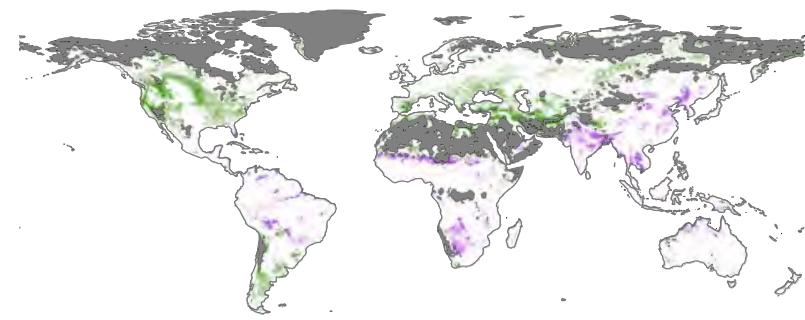

(ASCAT SM-10/30 - ASCAT SM-25/40): Difference R [-]

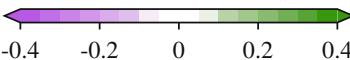

(c)

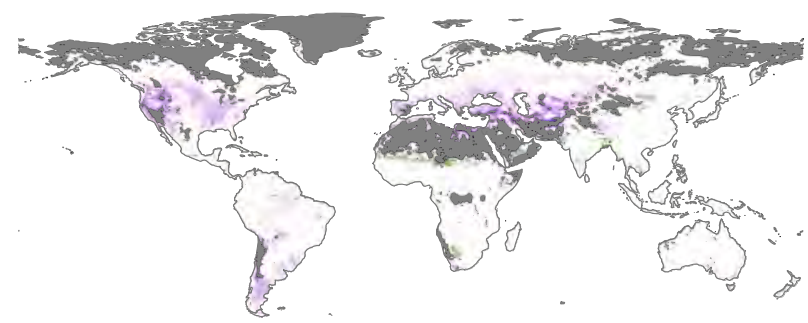

(ASCAT SM-40/40 - ASCAT SM-25/40): Difference R [-

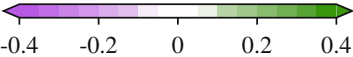

(d)

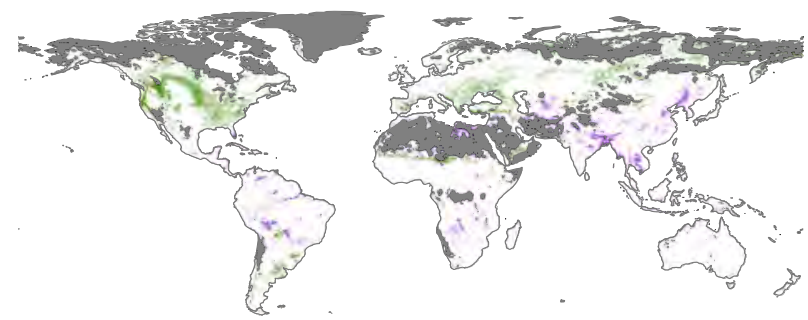

(ASCAT SM-Dyn - ASCAT SM-25/40): Difference R [-]

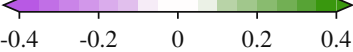

Fig. 7. Global maps of Pearson R ( $\mathrm{p}<0.05$ and more than 100 observations). Difference between Pearson R are only shown if both Pearson R values are positive.

error variance can be expressed in absolute terms, but as shown by [31], the obtained noise variance can be also related to the signal variance leading to the Signal-to-Noise Ratio (SNR). SNR expressed in decibel (dB) allows for a physical meaningful interpretation: if signal and noise variance are

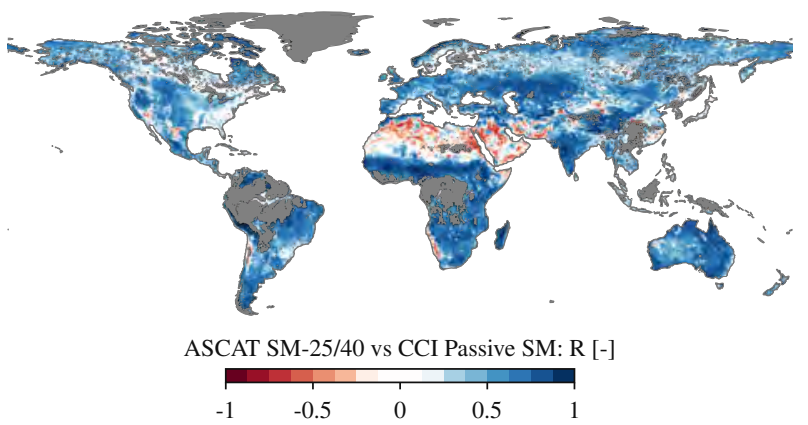

(b)

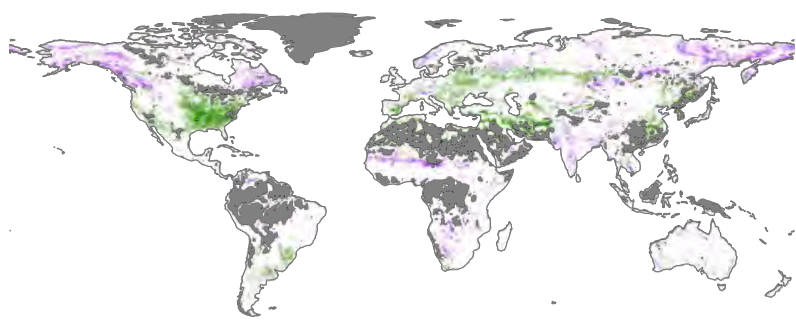

(ASCAT SM-10/30 - ASCAT SM-25/40): Difference R [-]

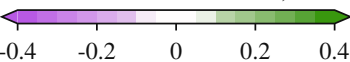

(c)

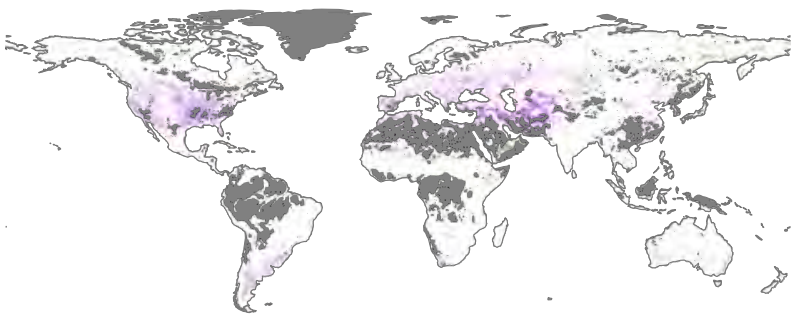

(ASCAT SM-40/40 - ASCAT SM-25/40): Difference R [-]

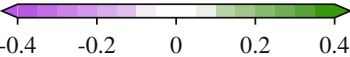

(d)

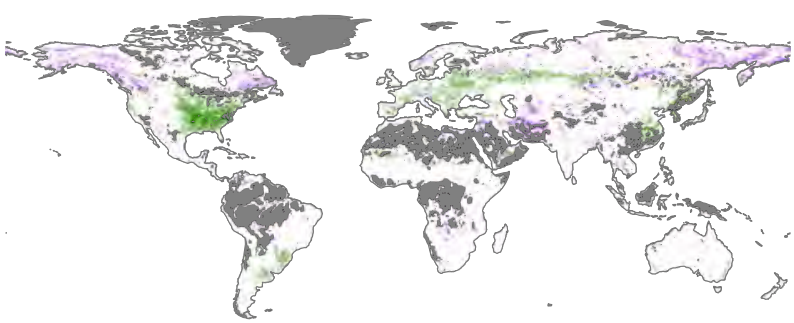

(ASCAT SM-Dyn - ASCAT SM-25/40): Difference R [-]

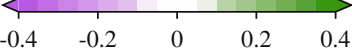

Fig. 8. Global maps of Pearson $\mathrm{R}$ ( $\mathrm{p}<0.05$ and more than 100 observations). Difference between Pearson $\mathrm{R}$ are only shown if both Pearson $\mathrm{R}$ values are positive.

equal, SNR is zero, whereas each doubling/halving of their ratio correspond to additional $\pm 3 \mathrm{~dB}$.

The temporal period under investigation was 2007-01-01 until 2018-12-31, which is covered by all soil moisture data sets. In order to calculate the validation metrics (R, SNR), 

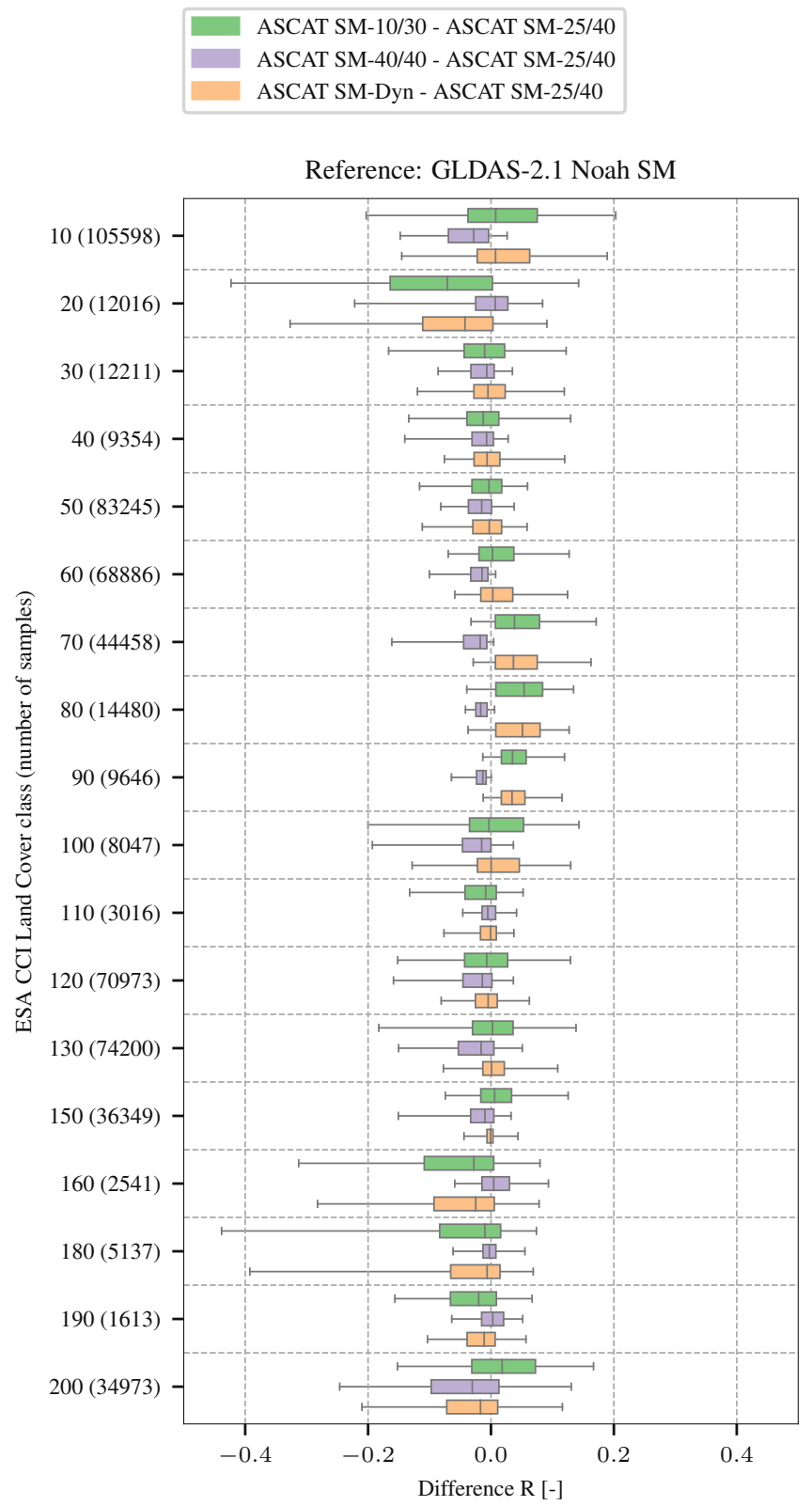

Fig. 9. Difference of Pearson R summarized as boxplot per land cover class using Noah GLDAS-2.1 SM as reference. Whisker ends represent 5th and 95th percentile.

a spatial and temporal collocation has been performed. In the spatial domain the WARP5 grid was used as a reference selecting nearest neighbors from the GLDAS-2.1 Noah and CCI Passive grid. In the temporal domain, the ASCAT soil moisture time stamps were used to find the closest corresponding soil moisture observation within \pm 8 hours from GLDAS2.1 Noah and CCI Passive. Time periods with frozen soil conditions and snow cover were masked out beforehand using soil temperature $\left(<4^{\circ}\right)$ and Snow Water Equivalent (SWE $>0$ ) information provided by GLDAS-2.1 Noah. The temporal matching was only performed between two data sets for the computation of Pearson R, while in case of TC the temporal matching was carried out between all three data sets.

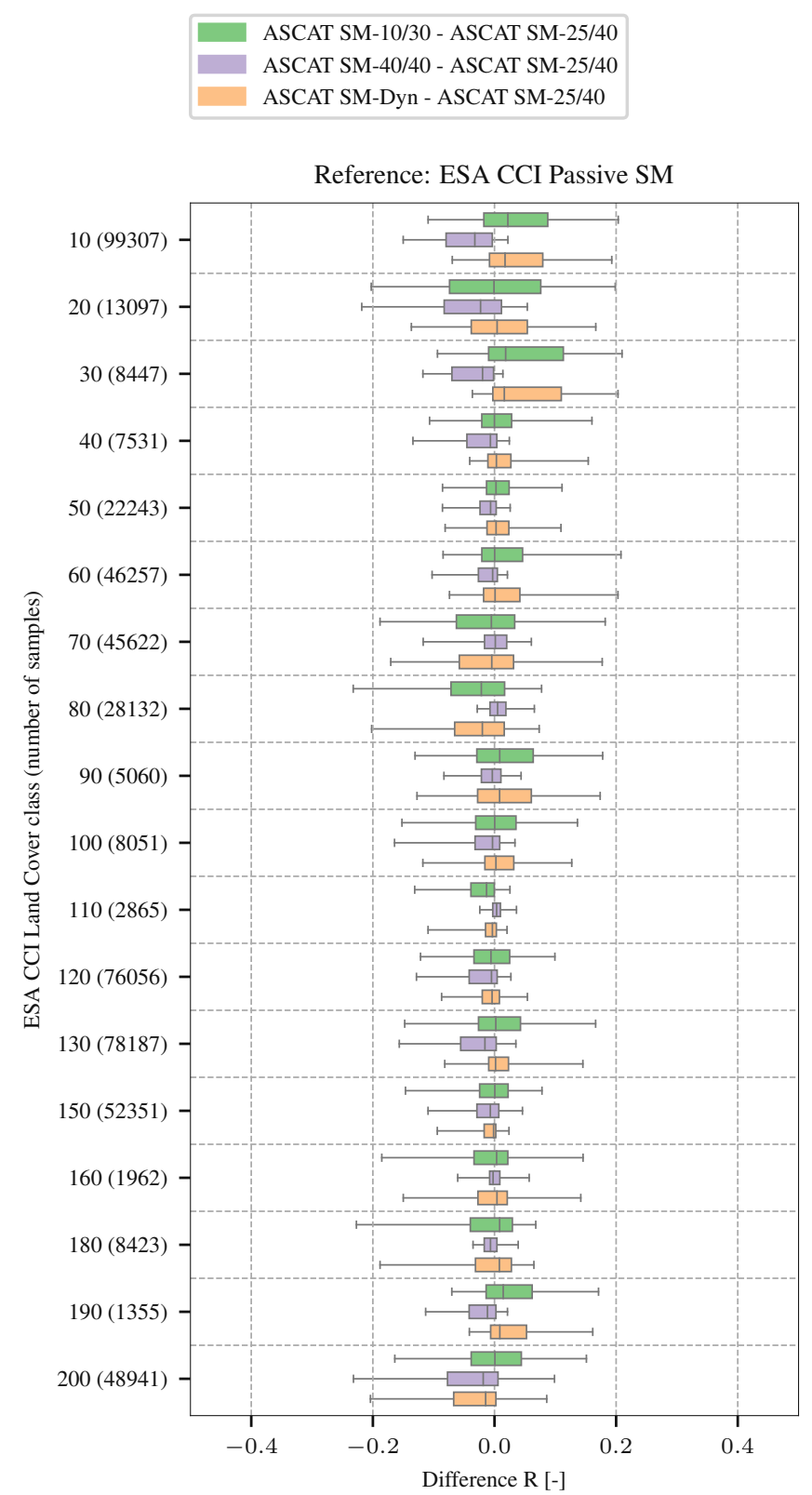

Fig. 10. Difference of Pearson R summarized as boxplot per land cover class using ESA CCI Passive SM as reference. Whisker ends represent 5th and 95th percentile.

\section{RESULTS AND DISCUSSION}

\section{A. Pearson $R$}

Figure 7 and Figure 8 show the result of Pearson $\mathrm{R}$ for ASCAT SM-25/40 and the difference against the other ASCAT SM data sets. Locations with $p$-values $<0.05$ are shown in Figure 7a and Figure 8a, whereas the difference of Pearson R (Figure 7b-7d and Figure 8b-8d) is only shown in case of positive correlations. Pearson R obtained from ASCAT SM25/40 and GLDAS-2.1 Noah SM (Figure 7a) shows large areas with good temporal correlations similar to Pearson R computed using ASCAT SM-25/40 and ESA CCI Passive SM (Figure 8a). However, both cases also indicate strong 


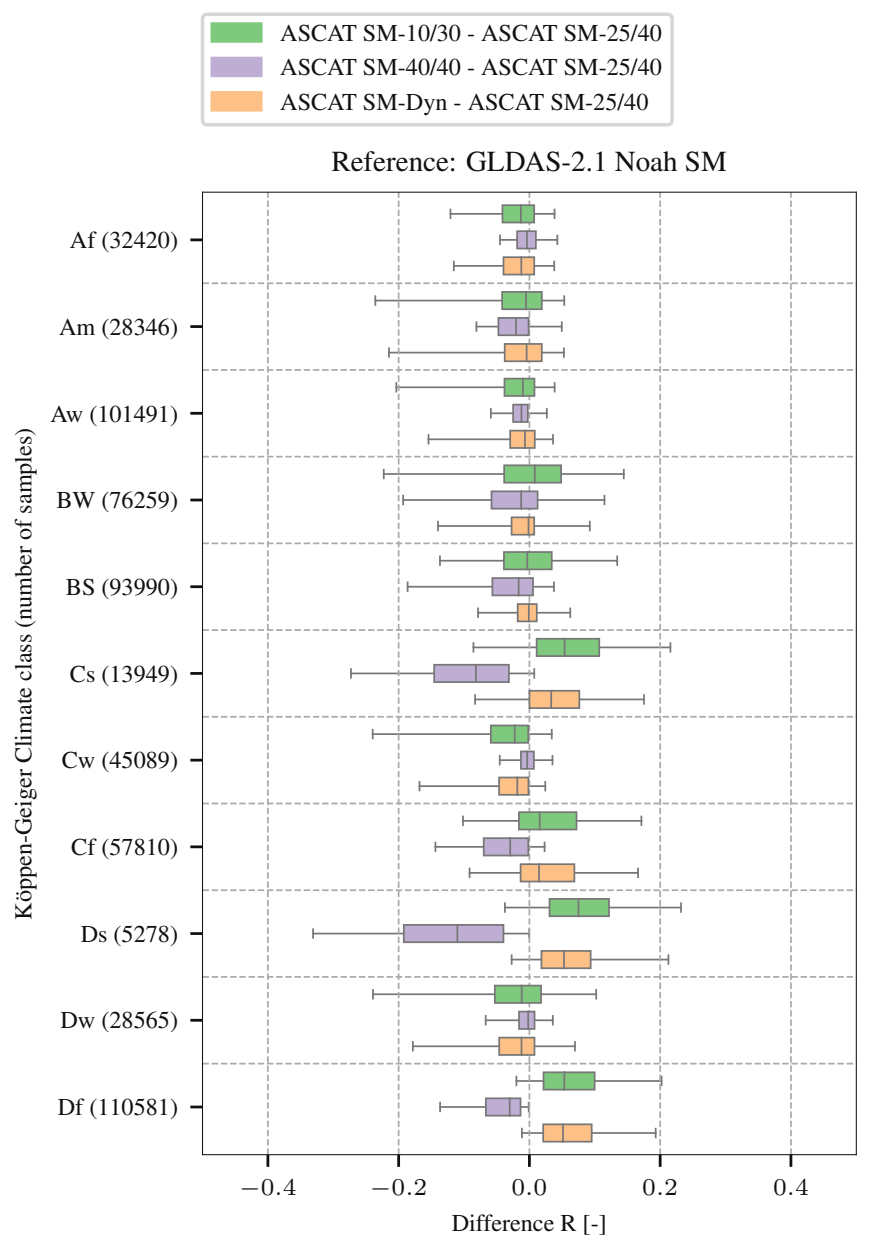

Fig. 11. Difference of Pearson $\mathrm{R}$ summarized as boxplot per Köppen Geiger climate class using Noah GLDAS-2.1 SM as reference. Whisker ends represent 5 th and 95 th percentile.

negative correlations visible in very dry regions (e.g. Arabian peninsula, North Africa, Namibia, Chile, US Arizona), which has been repeatedly shown by other studies as well [12], [50]-[52]. On-going research suggests that this could be due to subsurface scattering effects with an inverse relationship between backscatter and (low) soil moisture conditions: under very dry soil conditions deeper soil layers might cause volume scattering or scattering by subsurface discontinuities (e.g. bedrock or rocky layer covered by shallow soil), which is entirely obscured during wet soil conditions with an overall lower (surface) scattering intensity [11]. Such an effect has been observed in a field experiment for sandy soils in north central Florida using a L-band radar instrument [53] and also reproduced in an indoor laboratory experiment using C-band radar observations [54].

In addition, negative correlations can also be seen in high latitudes $\left(>65^{\circ} \mathrm{N}\right)$ in the case of GLDAS-2.1 Noah SM (Figure $7 \mathrm{a}$ ), although not as strong compared to dry environments. In general, northern latitudes present challenging retrieval conditions, especially for coarse resolution instruments such as ASCAT. For example, when frozen soil or snow dominates the instrument footprint, the retrieval of soil moisture is difficult or

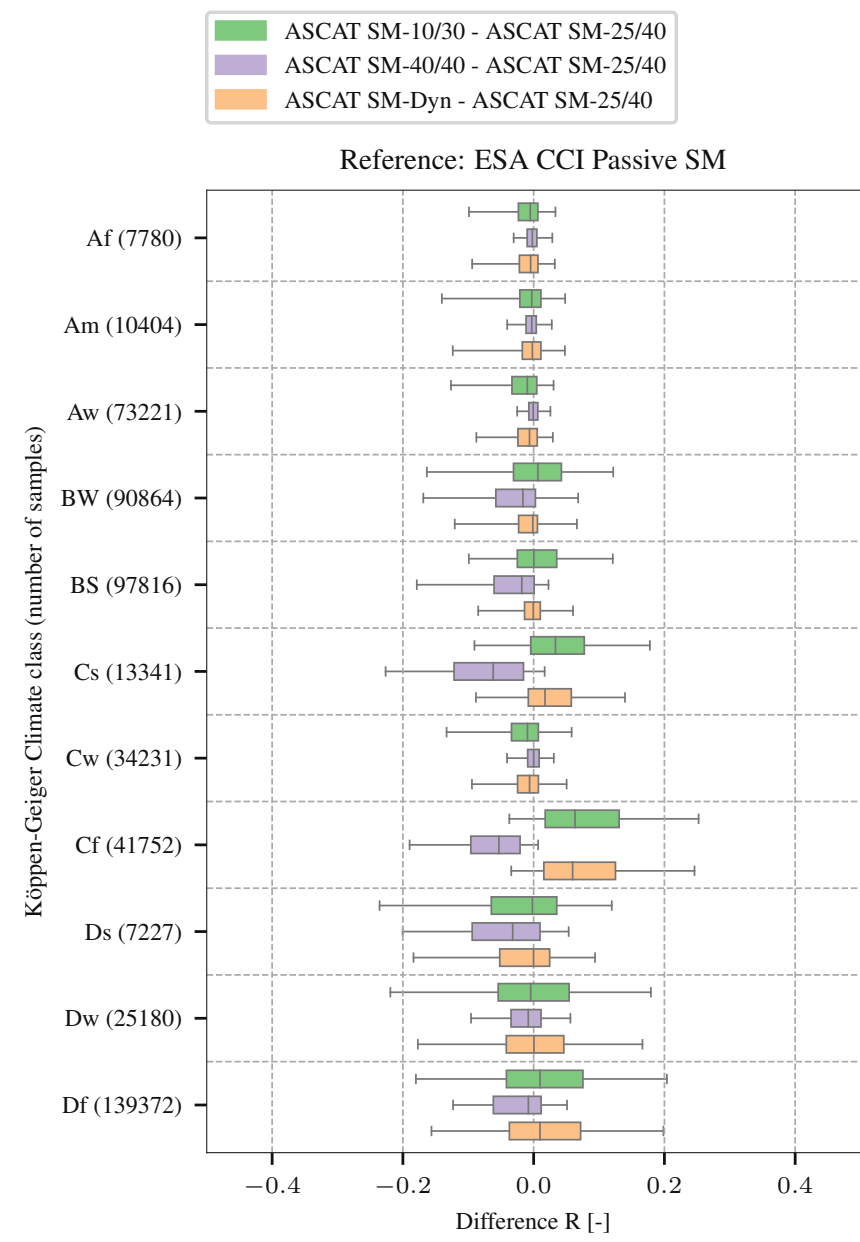

Fig. 12. Difference of Pearson R summarized as boxplot per Köppen Geiger climate class using ESA CCI Passive SM as reference. Whisker ends represent 5 th and 95 th percentile.

not possible at all. This is also true for transition periods with snow melt and (temporary) standing water [55], [56]. However, also the performance of land surface models is restricted in such environments, which, for example, depends on a correct parameterization of snow and frozen soil conditions [57]. Due to these two physical processes leading to negative correlations the differences in $\mathrm{R}$ are not shown (Figure $7 \mathrm{~b}-7 \mathrm{~d}$ and Figure $8 \mathrm{~b}-8 \mathrm{~d}$ ).

Figures $7 \mathrm{~b}$ and $7 \mathrm{c}$ illustrate the difference of Pearson $\mathrm{R}$ between ASCAT SM-25/40 and ASCAT SM-10/30, as well as ASCAT SM-25/40 and ASCAT SM-40/40 using GLDAS2.1 Noah SM as reference. Positive values indicate improvements with respect to the standard vegetation characterization $\left(\theta_{d}=25^{\circ}, \theta_{w}=40^{\circ}\right)$. North America, Europe and southern parts of South America show throughout a positive impact of using a stronger vegetation correction (ASCAT SM-10/30, Figure 7b), while a static-only vegetation correction (ASCAT SM-40/40, Figure 7c) leads to an overall lower performance compared to ASCAT SM-25/40. A similar pattern can be seen compared to ESA CCI Passive SM (Figures $8 b$ and 8c) except for some areas in high latitudes, which tend to be better for ASCAT SM-40/40. However, as mentioned before, high 
(a)

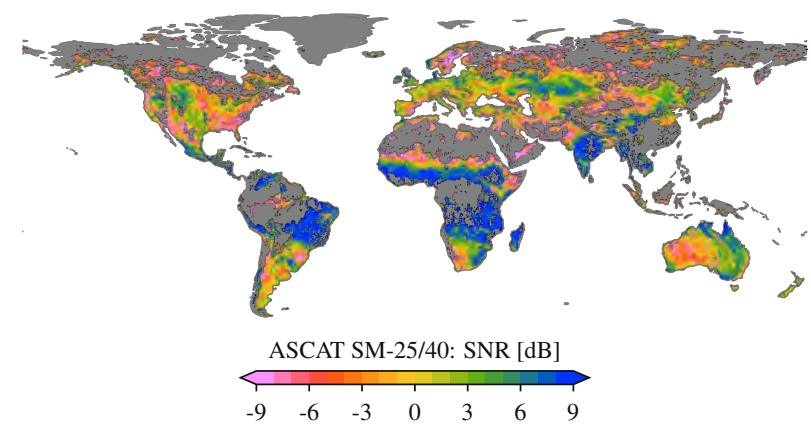

(b)

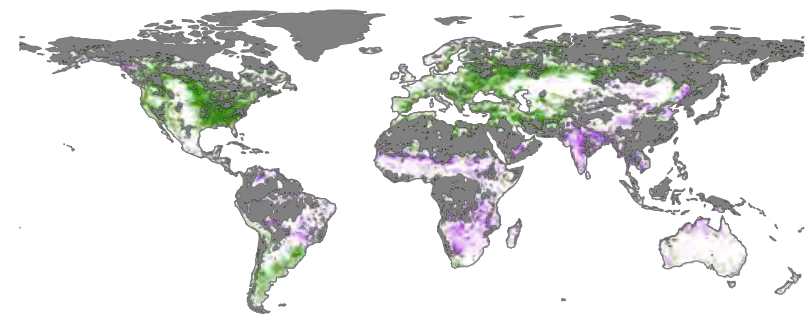

(ASCAT SM-10/30 - ASCAT SM-25/40): SNR [dB]

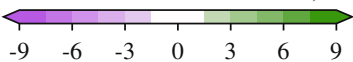

(c)

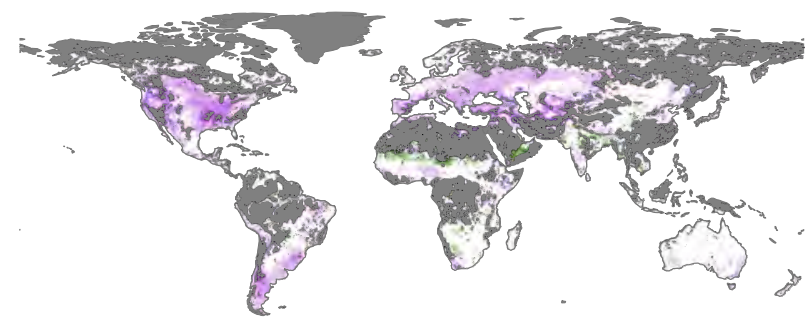

(ASCAT SM-40/40 - ASCAT SM-25/40): SNR [dB]

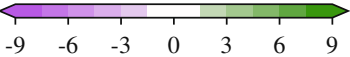

(d)

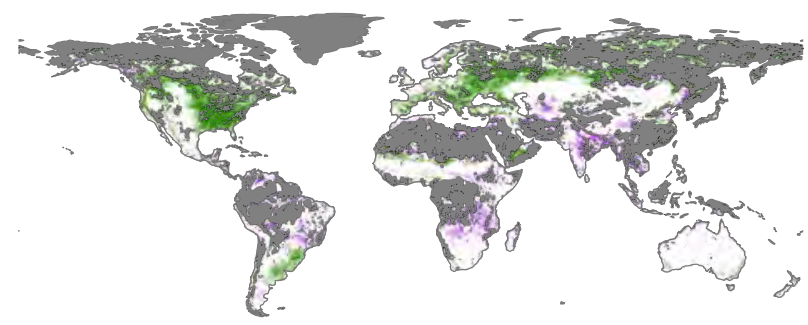

(ASCAT SM-Dyn - ASCAT SM-25/40): SNR [dB]

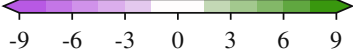

Fig. 13. Signal-to-Noise Ratio (SNR) estimated by TCA between ASCAT SM, GLDAS-2.1 Noah SM and CCI Passive SM. Locations only with more than 100 temporally colocated observations and a positive Pearson R between the data sets are shown.

latitudes are quite complex environments with an extended cold season leaving not many observations for validation. Poor results using a stronger vegetation correction are clearly visible in parts of Africa and East Asia, as well as India, Bolivia and Brazil (Figures $7 \mathrm{~b}$ and $8 \mathrm{~b}$ ). Interestingly, Pearson R tends to be

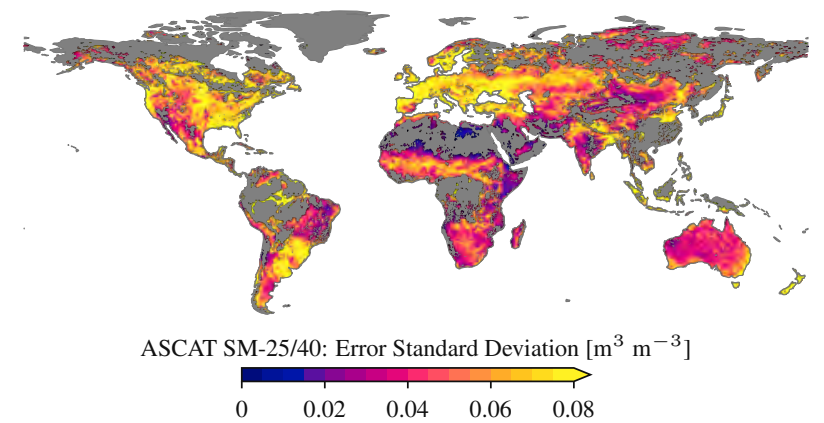

(b)

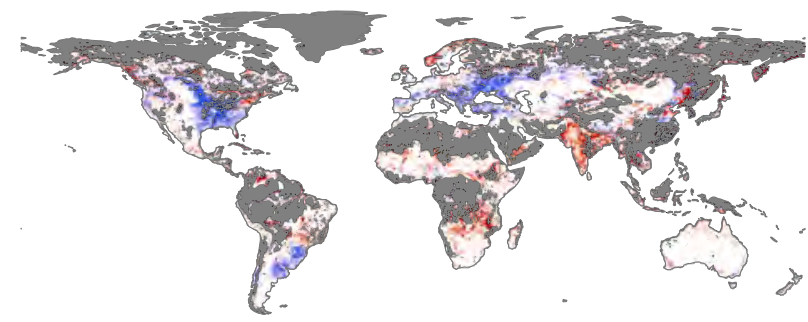

(ASCAT SM-10/30 - ASCAT SM-25/40): Error Standard Deviation $\left[\mathrm{m}^{3} \mathrm{~m}^{-3}\right]$

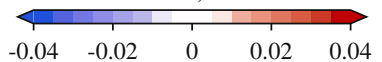

(c)

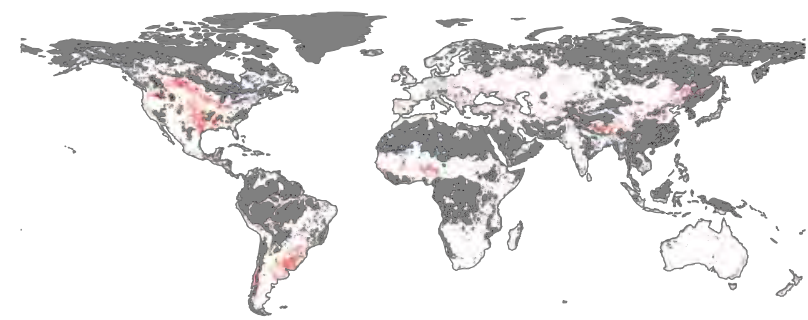

(ASCAT SM-40/40 - ASCAT SM-25/40): Error Standard Deviation $\left[\mathrm{m}^{3} \mathrm{~m}^{-3}\right]$ $\begin{array}{lllll}-0.04 & -0.02 & 0 & 0.02 & 0.04\end{array}$

(d)

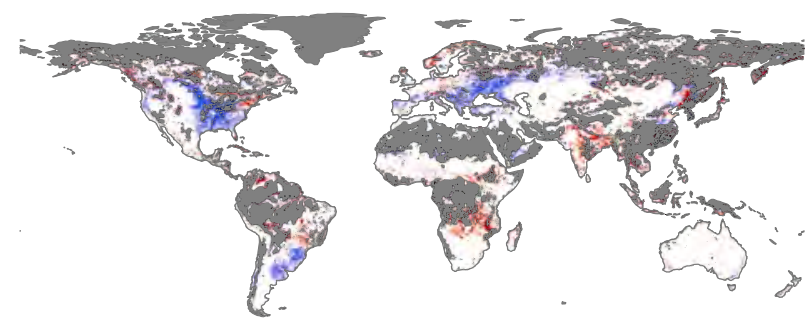

(ASCAT SM-Dyn - ASCAT SM-25/40): Error Standard Deviation $\left[\mathrm{m}^{3} \mathrm{~m}^{-3}\right]$ $\begin{array}{lllll}-0.04 & -0.02 & 0 & 0.02 & 0.04\end{array}$

Fig. 14. Error standard deviation estimated by TC between ASCAT SM, GLDAS-2.1 Noah SM and CCI Passive SM. Locations only with more than 100 temporally colocated observations and a positive Pearson R between the data sets are shown.

similar between ASCAT SM-25/40 and ASCAT SM-40/40 for exactly these areas (Figures $7 \mathrm{c}$ and $8 \mathrm{c}$ ). A closer examination of these regions shows that different reasons are causing this unexpected results.

Firstly, semi-arid regions, such as the Sahel zone and South 


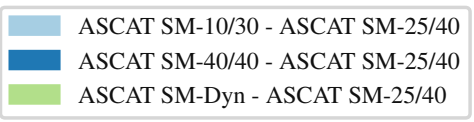

Reference: GLDAS-2.1 Noah SM, ESA CCI Passive SM

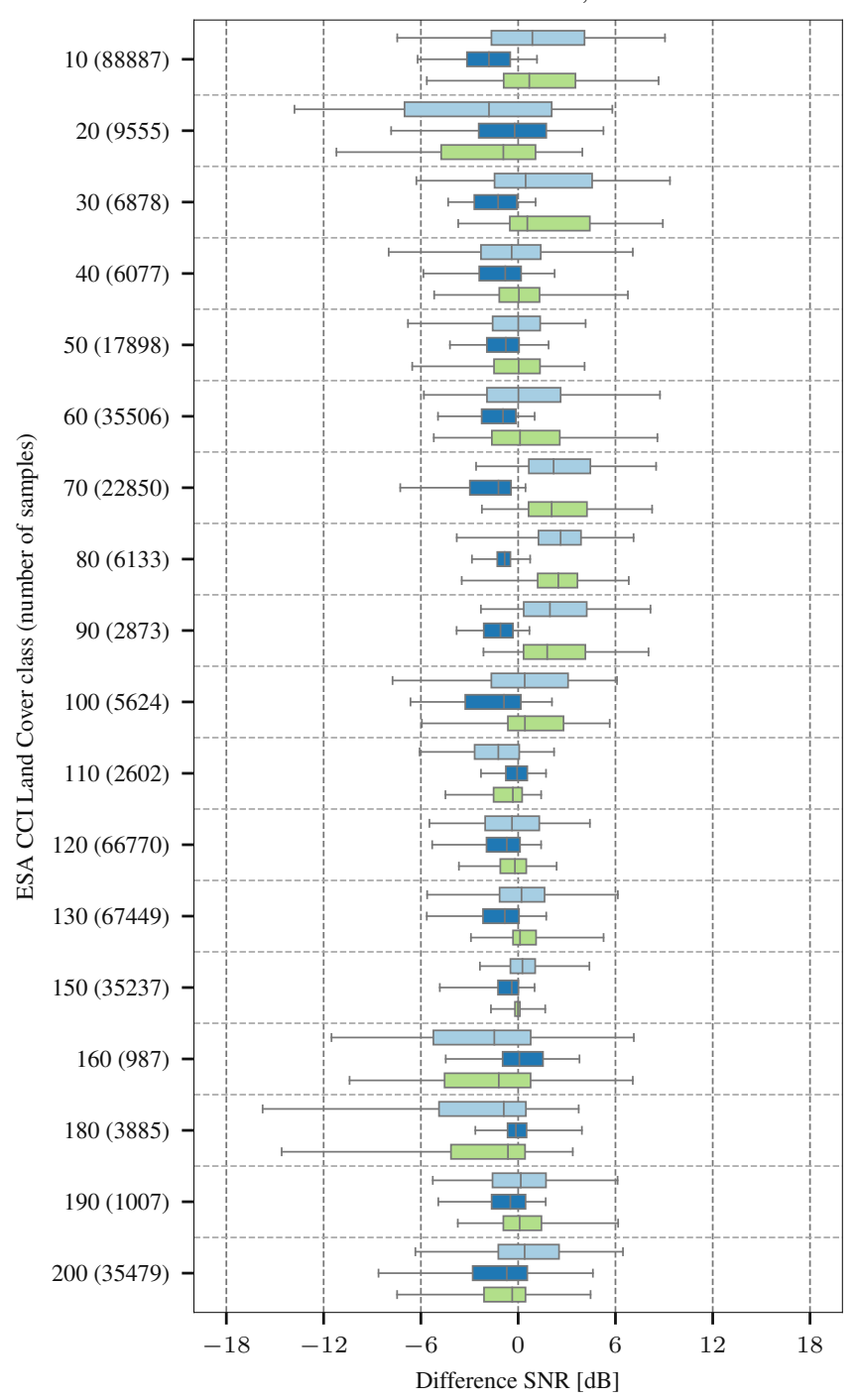

Fig. 15. Difference of SNR summarized as boxplot per land cover class. Whisker ends represent 5 th and 95 th percentile.

Africa, exhibit a high level of variation in their seasonal soil moisture and vegetation dynamics. For example, these areas can suffer from large scale disruptions, such as fires and subsequent multi-annual recoveries. Therefore, the assumption that a climatology is able to represent the interannual cycle of vegetation phenology might be insufficient. This was also shown by [20] who demonstrated that the TUWSMR soil moisture retrievals improved when using a interannually varying vegetation correction based on VOD from passive microwave observations. More in-depth analysis in South Africa have indicated (not shown) that incorrect (not dry) backscatter observations are selected to determine the dry reference. Hence, a misrepresentation of the inter-annual vegetation cycle using a climatology of $\sigma^{\prime}$ and $\sigma^{\prime \prime}$ is one of
ASCAT SM-10/30 - ASCAT SM-25/40 ASCAT SM-40/40 - ASCAT SM-25/40 ASCAT SM-Dyn - ASCAT SM-25/40

Reference: GLDAS-2.1 Noah SM, ESA CCI Passive SM

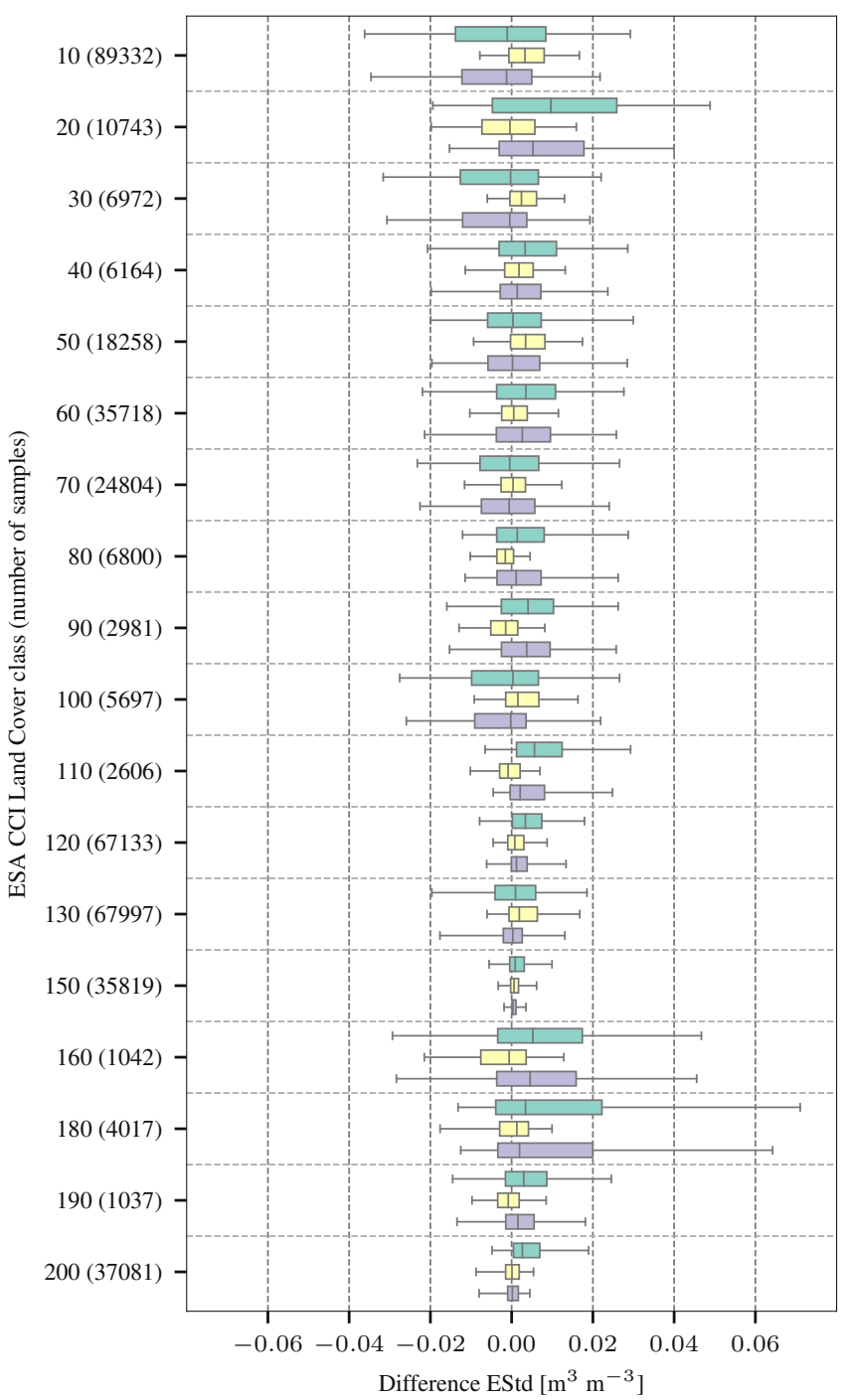

Fig. 16. Difference of Error Standard Deviation summarized as boxplot per land cover class. Whisker ends represent 5th and 95th percentile.

the reason why the lowest backscatter extrapolated to the dry cross-over angle no longer corresponds to driest soil moisture conditions.

Secondly, the poor performance in India, Bolivia, Brazil and part of East Asia are related to wetlands. Some of the worlds largest wetlands are clearly visible, such as the Amazon River Floodplain, the Pantanal in South America and the Sundarbans in the Ganges-Brahmaputra Delta. In Africa, the outline of numerous Zambezian flooded grasslands (e.g Okavango Delta, Bangweulu Wetlands, Lukanga Swamp) can be detected. Wetland backscatter signatures are quite unique because the dominant scattering mechanism ranges from surface and volume scattering to specular reflection and double-bounce effects [58]. Therefore, temporal changes in the 


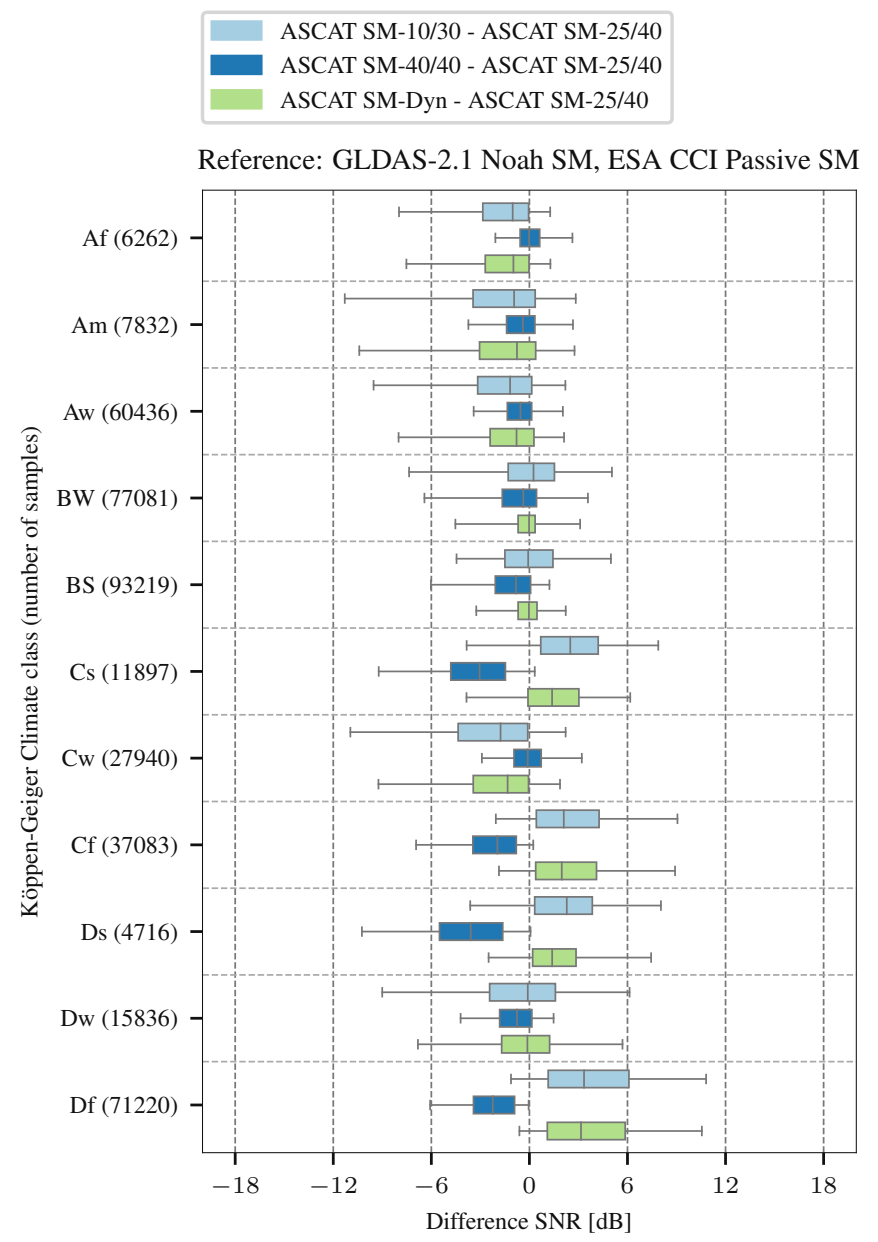

Fig. 17. Difference of SNR summarized as boxplot per Köppen Geiger climate class. Whisker ends represent 5th and 95th percentile.

incidence angle dependency of backscatter are mainly driven by changes in the scattering mechanism. Further enhancing the vegetation correction may increase already existing errors due to an incorrect representation of the scattering behavior, ultimately misinterpreting vegetation phenology. Similar to the situation in high latitudes, an accurate retrieval of surface soil moisture information is quite complex or impossible in wetlands. Flooding dynamics and vegetation coverage are the main problems. However, Synthetic Aperture Radar (SAR) systems have shown good results mapping and monitoring wetland changes (e.g. [59]), but coarse scale instruments, such as ASCAT, have a clear handicap.

Finally, a large part of negative Pearson $\mathrm{R}$ results using a stronger vegetation correction can be linked to flooded cropland, e.g. visible in Thailand, India and China. Similar to wetlands, emergent vegetation from continuously or periodically inundated cropland can lead to multiple scattering mechanism affecting the temporal behavior of $\sigma^{\prime}$ and $\sigma^{\prime \prime}$. In addition, the climatological representation of $\sigma^{\prime}$ and $\sigma^{\prime \prime}$ can have a negative impact on both, wetlands and flooded cropland. As previously mentioned, strong inter-annual variations can lead to extrapolation errors selecting the wrong backscatter observations for the determination of the dry and wet backscatter

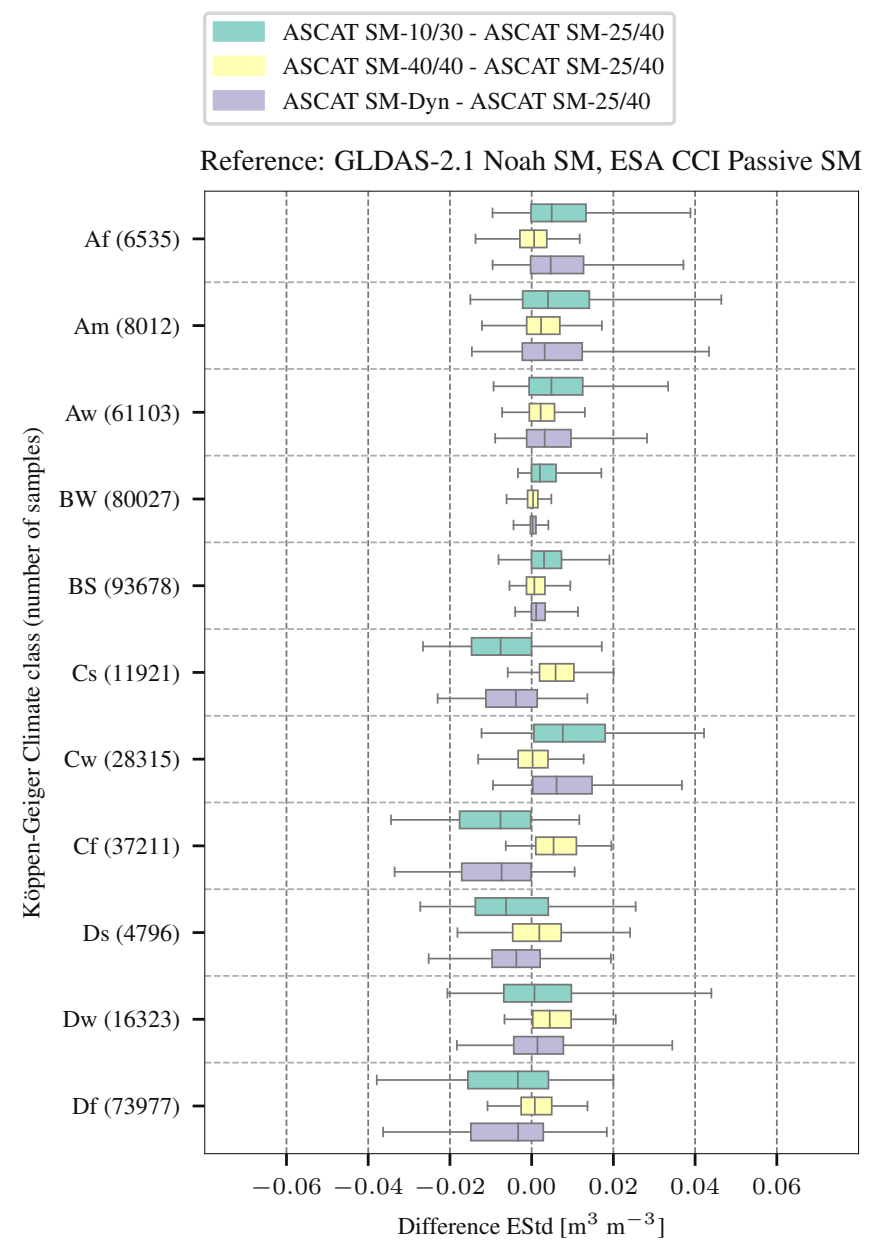

Fig. 18. Difference of Error Standard Deviation summarized as boxplot per Köppen Geiger climate class. Whisker ends represent 5th and 95th percentile.

reference. In fact, the TUW-SMR has not been developed to model backscatter behavior of flooded vegetation. Therefore, an optimization of the vegetation parameterization will not help in such situations.

Combining the results of Pearson R between ASCAT SM and GLDAS-2.1 Noah SM in CCI Land Cover classes [49] (Figure 9) and Köppen Geiger climate classes [48] (Figure 11), shows that tree cover land cover classes $(70,80,90)$, as well as cold $(\mathrm{Cs}, \mathrm{Cf})$ and temperate (Ds, Df) climates benefit the most from a stronger vegetation correction. Moreover, the performance clearly deteriorates in case of flooded vegetation $(20,160,180)$. The latter is in line with previous observations and discussions on mixed scattering behavior in such regions. Interestingly, in some cases the standard vegetation correction seems to be superior, most notably in cropland (20) and shrubland (120).

The performance of ASCAT SM-Dyn is very similar to ASCAT SM-10/30, which is expected because the spatiallyvariable cross-over angles are close to $\theta_{d}=10^{\circ}$ and $\theta_{w}=30^{\circ}$ over large parts of the world. The exception are sparsely vegetated and bare areas, where the cross-over angles are shifting towards $\theta_{d}=40^{\circ}$ and $\theta_{w}=40^{\circ}$ leading to no seasonal vegetation correction. Therefore, ASCAT SM-Dyn 
has the advantage of showing a good performance in similar areas as ASCAT SM-10/30 compared to ASCAT SM-25/40, while at the same time avoiding an inaccurate and erroneous (seasonal) vegetation correction in areas previously discussed (Figure 7d).

In case of ASCAT SM and CCI Passive SM (Figure 10 and Figure 12) the Pearson $\mathrm{R}$ results show smaller improvements of ASCAT SM-10/30, illustrating that $\theta_{d}=25^{\circ}$ and $\theta_{w}=40^{\circ}$ have been a good choice on a global basis. However, the performance consistently improves for the cropland classes $(10,20,30)$ and cold (Cs, Cf) climates. Similar to GLDAS-2.1 Noah SM, the comparison against ESA CCI Passive SM also shows comparable results between ASCAT SM-Dyn and ASCAT SM-10/30, but again with the same advantage of ASCAT SM-Dyn containing less areas with a poor performance.

It has also been tested whether performance differences can be detected computing soil moisture anomalies using a sliding window of five weeks similar to [60]. However, the remaining soil moisture anomaly contains only short term variations and the performance metrics indicate no significant difference for the ASCAT SM data sets (not shown) as the vegetation parameterization affects the seasonality of soil moisture more than short-term changes.

\section{B. Triple Collocation}

The error variance computed using Triple Collocation (TC) are presented as Signal-to-Noise Ratio (SNR) in Figure 13 and scaled error standard deviation (EStd) in Figure 14. While EStd indicates errors only, SNR presents errors with respect to the signal variance on a logarithmic scale [31].

TC has been applied four times, each time using Noah GLDAS-2.1 SM and CCI Passive SM in combination with a different ASCAT SM data set (see Table III). The results of SNR and EStd are shown in Figure 13 and Figure 14 only for locations having a positive Pearson $\mathrm{R}$ and at least more than 100 temporally collocated soil moisture triplets. The SNR and EStd of ASCAT SM-25/40 (Figure 13a and Figure 14a) have been used as a baseline and the difference to all other ASCAT SM data sets has been computed.

As can be seen in Figure 13b, a stronger vegetation correction (ASCAT SM-10/30) tends to improve SNR especially in the Northern Hemisphere. Many parts of North America and Europe increase from around $0 \mathrm{~dB}$ to more than 3$6 \mathrm{~dB}$ indicating a substantial improvement in terms of SNR. However, an exceptional decrease of SNR can be also detected, e.g. in India and South Africa dropping more than $3 \mathrm{~dB}$ in some parts. As previously discussed in case of Pearson R, the climatological representation of the vegetation phenology in combination with mixed scattering mechanism are compromising the soil moisture retrieval, which becomes more evident using a stronger vegetation correction (ASCAT SM-10/30). The spatially-variable characterization of the cross-over angles (ASCAT SM-Dyn) produces more balanced results with less strong negative SNR results (Figure 13d) compared to ASCAT SM-10/30 indicating that a static vegetation correction (like in ASCAT SM-40/40) seems to be the best case scenario at the moment in areas such as Africa and India (Figure 13c) (a)

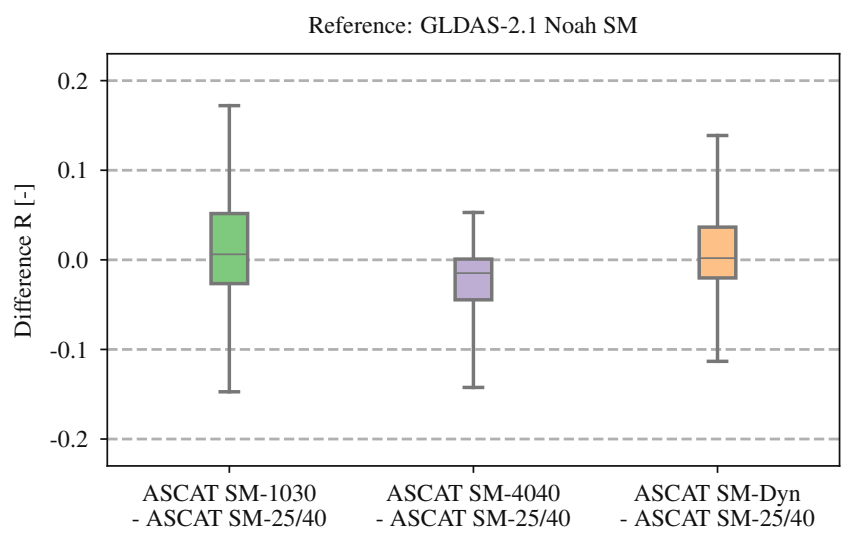

(b)

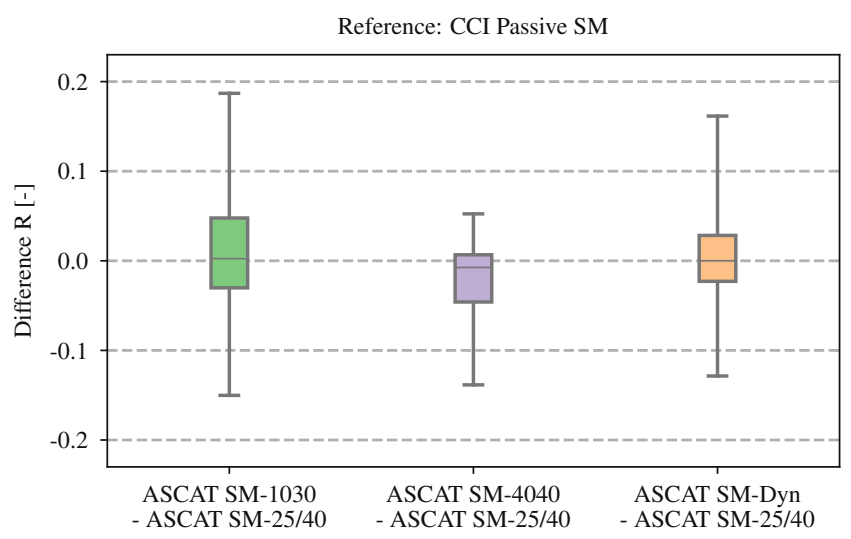

(c)

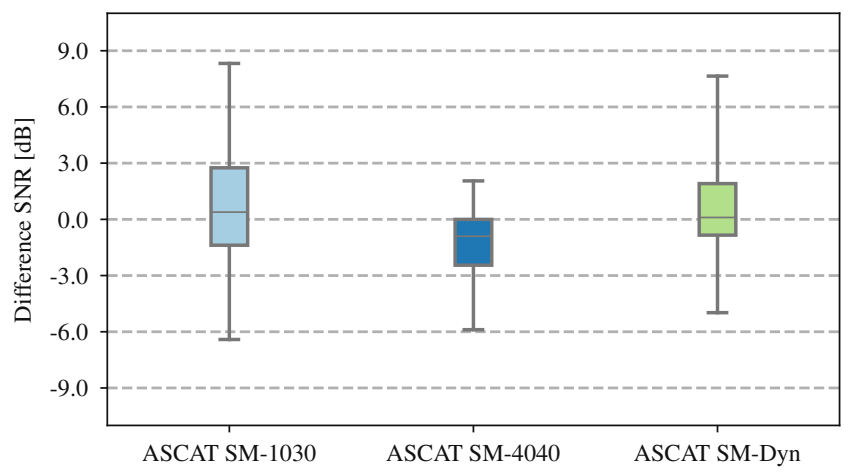

(d)

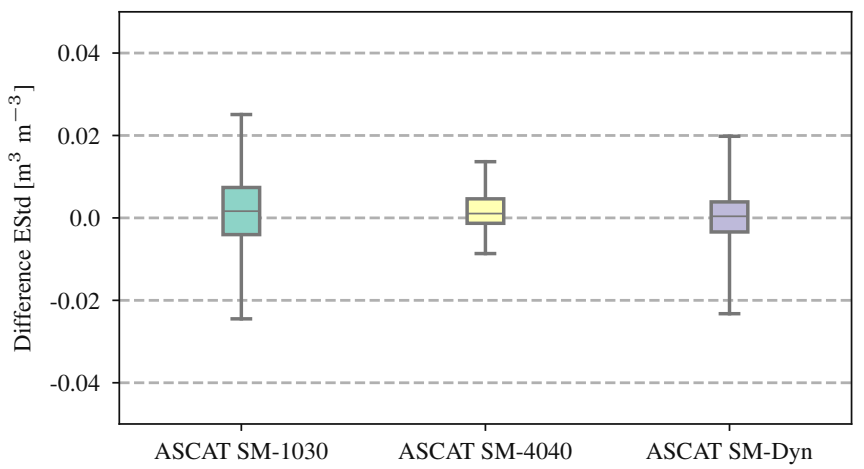

Fig. 19. Difference of Pearson R in case of GLDAS-2.1 Noah SM (a) and CCI Passive SM (b), as well as difference of SNR (c) and EStd (d) summarized as boxplots. Whisker ends represent 5th and 95th percentile. 
before better characterizing the inter-annual vegetation cycle. Otherwise a seasonal vegetation correction has a clear benefit as can be seen in Figure 13c, because many areas indicate a negative SNR.

A similar spatial pattern can be found in the case of EStd, representing the scaled error standard deviation. Smaller errors can be found in Eastern Europe and Eastern U.S. for ASCAT SM-10/30 (Figure 14b), as well as countries like Argentina and Uruguay which also benefit from a stronger vegetation correction when compared to ASCAT SM-25/40. As evident in Figure 14c, there are no large differences in EStd between ASCAT SM-25/40 and ASCAT SM-40/40. This suggests, that the soil moisture benefits most from applying a seasonal vegetation correction, which becomes even more evident for ASCAT SM-10/30 and ASCAT SM-Dyn.

Like Pearson R, aggregating SNR in terms of CCI Land Cover classes (Figure 15) and Köppen Geiger climate classes (Figure 17) shows better results for tree cover (60, 70, 80, $90,100)$ and crop classes $(10,30)$, as well as cold (Cs, Cf) and temperate climates (Ds, Df). A direct comparison between SNR and EStd suggest that especially tree cover classes (70, $80,90)$ gain in terms of signal variance since the median of EStd remains overall close to zero. Looking at areas containing flooded vegetation $(20,160,180)$ reveals a higher EStd with an overall reduction of SNR for ASCAT SM-10/30 and ASCAT SM-Dyn, which is consistent with the results based on Pearson R.

\section{CONCLUSION AND OUTLOOK}

In this study we investigated the performance of the TU Wien soil moisture retrieval algorithm using different pairs of dry and wet cross-over angles: (i) $\theta_{d}=40^{\circ}$ and $\theta_{w}=40^{\circ}$ which is equivalent to no respectively static vegetation correction, (ii) $\theta_{d}=25^{\circ}$ and $\theta_{w}=40^{\circ}$ representing the current (standard) seasonal vegetation correction, (iii) $\theta_{d}=10^{\circ}$ and $\theta_{w}=30^{\circ}$ describing a stronger seasonal vegetation correction and (iv) a spatially-variable choice of cross-over angles derived from a Vegetation Continuous Fields (VCF) data set. A comparison against GLDAS-2.1 Noah SM and ESA CCI Passive SM v04.5 showed that a better performance in terms of Pearson $\mathrm{R}$ and SNR can be achieved using a stronger vegetation correction (ASCAT SM-10/30), which was particularly the case for many parts of North America and Europe. The ASCAT soil moisture data record based on the spatially-variable selection of cross-over angles (ASCAT SMDyn) indicated also a good performance compared to the current seasonal vegetation correction (ASCAT SM-25/40), but with the advantage that over bare or sparsely vegetated land the vegetation correction is switched off. Over vegetated areas the results of ASCAT SM-40/40 generally showed a lower performance compared to the parameterisations modelling a seasonal vegetation signal (ASCAT SM-25/40, ASCAT SM10/30, ASCAT SM-Dyn). Hence, these results confirm the value of the information contained in the ASCAT observed slope $\sigma^{\prime}$ and curvature $\sigma^{\prime \prime}$ for describing vegetation dynamics [61] and illustrate that it is not enough to just take normalising backscatter time series for estimating soil moisture as this causes seasonal biases.
The analysis also provided insight into challenging conditions where the TU Wien soil moisture retrieval algorithm fails to describe all relevant backscatter phenomena, such as subsurface scattering in dry areas or regions with (temporary) flooded vegetation (e.g. wetlands, flooded cropland). Furthermore, we identified a shortcoming related to the climatological characterization of the vegetation cycle. A previous study has tried characterizing $\sigma^{\prime}$ and $\sigma^{\prime \prime}$ as time series based on a kernel smoother showing promising results [62], however, further work is needed to combine this method with the new selection of cross-over angles investigated in this study. In addition, the assumptions behind the TU Wien soil moisture retrieval algorithm have been tested and evaluated against a newly developed radiative transfer model (RT1) [63], which has been recently applied to ASCAT [64]. RT1 has shown a very similar functional behavior, but also differences e.g. suggesting a certain dependency between slope and soil moisture. Further research is planned on this subject.

The initial selection of the cross-over angles $\left(\theta_{d}=25^{\circ}\right.$ and $\theta_{w}=40^{\circ}$ ) has been a robust and effective choice [10], [22], [24], but based on the results presented in this study a stronger vegetation correction helps to improve the ASCAT soil moisture signal (Figure 13b and Figure 13d). Quantitatively ASCAT SM-10/30 and ASCAT SM-Dyn are showing a similar performance, with less extreme values in case of ASCAT SM-Dyn (Figure 19). Apart from that, a spatiallyvariable cross-over angle selection is preferable eventually (ASCAT SM-Dyn), because it allows further adjustment of the optimal choice of cross-over angles. In fact, some areas still indicate ASCAT SM-25/40 as the best compromise. Therefore, our recommendation for the operational H SAF ASCAT soil moisture data services [11] is to adopt the new spatiallyvariable vegetation parameterization introduced here.

A new generation of C-band scatterometer instrument (called SCA) is currently being prepared and foreseen to be launched in 2024. The SCA instrument will be on-board the Metop Second Generation (Metop-SG) satellite representing the space segment of the EUMETSAT Polar System - Second Generation (EPS-SG). The new Metop-SG constellation will contain three pairs of satellites, i.e. 6 satellites (A1-A3, B1B3), instead of 3 in case of Metop (A, B, C). SCA will be on-board of the B series of the Metop-SG satellites ensuring C-band backscatter measurements until 2040. Apart from an improved radiometric and spatial resolution of SCA compared to ASCAT, a new feature will be an additional VH channel on SCA's Mid beam antennas [65]. This additional source of information can be vital to further optimize and improve vegetation characterization in the TU Wien soil moisture retrieval algorithm.

\section{ACKNOWLEDGMENT}

The authors acknowledge funding from the EUMETSAT Satellite Application Facility on Support to Operational Hydrology and Water Management (H SAF) and support from the Austrian Space Application Programme through the BMon (No. 872408) and DWC-Radar (No. 873658) projects. 


\section{REFERENCES}

[1] E. G. Njoku and P. E. O'Neill, "Multifrequency Microwave Radiometer Measurements of Soil Moisture," IEEE Transactions on Geoscience and Remote Sensing, vol. GE-20, no. 4, pp. 468-475, Oct. 1982.

[2] T. J. Schmugge, "Remote Sensing of Soil Moisture: Recent Advances," IEEE Transactions on Geoscience and Remote Sensing, vol. GE-21, no. 3, pp. 336-344, Jul. 1983.

[3] E. T. Engman and N. Chauhan, "Status of microwave soil moisture measurements with remote sensing," Remote Sensing of Environment, vol. 51, no. 1, pp. 189-198, Jan. 1995.

[4] M. Owe, R. de Jeu, and J. Walker, "A methodology for surface soil moisture and vegetation optical depth retrieval using the microwave polarization difference index," IEEE Transactions on Geoscience and Remote Sensing, vol. 39, no. 8, pp. 1643-1654, Aug./2001.

[5] E. Njoku, T. Jackson, V. Lakshmi, T. Chan, and S. Nghiem, "Soil moisture retrieval from AMSR-E," IEEE Transactions on Geoscience and Remote Sensing, vol. 41, no. 2, pp. 215-229, Feb. 2003.

[6] R. M. Parinussa, T. R. H. Holmes, N. Wanders, W. A. Dorigo, and R. A. M. de Jeu, "A Preliminary Study toward Consistent Soil Moisture from AMSR2," Journal of Hydrometeorology, vol. 16, no. 2, pp. 932947, Apr. 2015.

[7] R. Bindlish, T. Jackson, M. Cosh, T. Zhao, and P. O’Neill, "Global Soil Moisture From the Aquarius/SAC-D Satellite: Description and Initial Assessment," IEEE Geoscience and Remote Sensing Letters, vol. 12, no. 5, pp. 923-927, May 2015

[8] Y. H. Kerr, P. Waldteufel, J.-P. Wigneron, S. Delwart, F. Cabot, J. Boutin, M.-J. Escorihuela, J. Font, N. Reul, C. Gruhier, S. E. Juglea, M. R. Drinkwater, A. Hahne, M. Martín-Neira, and S. Mecklenburg, "The SMOS Mission: New Tool for Monitoring Key Elements of the Global Water Cycle," Proceedings of the IEEE, vol. 98, pp. 666-687, May 2010.

[9] D. Entekhabi, E. G. Njoku, P. E. O'Neill, K. H. Kellogg, W. T. Crow, W. N. Edelstein, J. K. Entin, S. D. Goodman, T. J. Jackson, J. Johnson, J. Kimball, J. R. Piepmeier, R. D. Koster, N. Martin, K. C. McDonald, M. Moghaddam, S. Moran, R. Reichle, J. C. Shi, M. W. Spencer, S. W. Thurman, L. Tsang, and J. Van Zyl, "The Soil Moisture Active Passive (SMAP) Mission," Proceedings of the IEEE, vol. 98, no. 5, pp. 704-716, May 2010.

[10] W. Wagner, G. Lemoine, and H. Rott, "A method for estimating soil moisture from ERS scatterometer and soil data," Remote Sensing of Environment, vol. 70, no. 2, pp. 191-207, 1999.

[11] W. Wagner, S. Hahn, R. Kidd, T. Melzer, Z. Bartalis, S. Hasenauer, J. Figa-Saldaña, P. de Rosnay, A. Jann, S. Schneider, J. Komma, G. Kubu, K. Brugger, C. Aubrecht, J. Züger, U. Gangkofner, S. Kienberger, L. Brocca, Y. Wang, G. Blöschl, J. Eitzinger, K. Steinnocher, P. Zeil, and F. Rubel, "The ASCAT Soil Moisture Product: A Review of its Specifications, Validation Results, and Emerging Applications,' Meteorologische Zeitschrift, vol. 22, no. 1, pp. 5-33, Feb. 2013.

[12] Y. Y. Liu, R. M. Parinussa, W. A. Dorigo, R. A. M. D. Jeu, W. Wagner, A. I. J. M. van Dijk, M. F. McCabe, and J. P. Evans, "Developing an improved soil moisture dataset by blending passive and active microwave satellite-based retrievals," Hydrology and Earth System Sciences, vol. 15, no. 2, pp. 425-436, feb 2011.

[13] Y. Liu, W. Dorigo, R. Parinussa, R. de Jeu, W. Wagner, M. McCabe, J. Evans, and A. van Dijk, "Trend-preserving blending of passive and active microwave soil moisture retrievals," Remote Sensing of Environment, vol. 123, pp. 280-297, aug 2012.

[14] F. T. Ulaby, R. K. Moore, and A. K. Fung, Microwave Remote Sensing: Active and Passive. Vol. III - Volume Scattering and Emission Theory, Advanced Systems and Applications. Dedham, MA, USA: Artech House, Inc., 1986.

[15] T. Jackson and T. Schmugge, "Vegetation effects on the microwave emission of soils," Remote Sensing of Environment, vol. 36, no. 3, pp. 203-212, Jun. 1991.

[16] S. Paloscia, G. Macelloni, E. Santi, and T. Koike, "A multifrequency algorithm for the retrieval of soil moisture on a large scale using microwave data from SMMR and SSM/I satellites," IEEE Transactions on Geoscience and Remote Sensing, vol. 39, no. 8, pp. 1655-1661, Aug./2001.

[17] J. Kolassa, F. Aires, J. Polcher, C. Prigent, C. Jimenez, and J. M. Pereira, "Soil moisture retrieval from multi-instrument observations: Information content analysis and retrieval methodology: SOIL MOISTURE RETRIEVAL METHODOLOGY," Journal of Geophysical Research: Atmospheres, vol. 118, no. 10, pp. 4847-4859, May 2013.

[18] Li Li, P. W. Gaiser, Bo-Cai Gao, R. M. Bevilacqua, T. J. Jackson, E. G. Njoku, C. Rudiger, J.-C. Calvet, and R. Bindlish, "WindSat Global Soil
Moisture Retrieval and Validation," IEEE Transactions on Geoscience and Remote Sensing, vol. 48, no. 5, pp. 2224-2241, May 2010.

[19] Y. Kerr, P. Waldteufel, J.-P. Wigneron, J. Martinuzzi, J. Font, and M. Berger, "Soil moisture retrieval from space: The Soil Moisture and Ocean Salinity (SMOS) mission," IEEE Transactions on Geoscience and Remote Sensing, vol. 39, pp. 1729-1735, Aug./2001.

[20] M. Vreugdenhil, W. A. Dorigo, W. Wagner, R. A. M. de Jeu, S. Hahn, and M. J. E. van Marle, "Analyzing the vegetation parameterization in the TU-wien ASCAT soil moisture retrieval," IEEE Transactions on Geoscience and Remote Sensing, vol. 54, no. 6, pp. 3513-3531, jun 2016.

[21] Z. Bartalis, W. Wagner, V. Naeimi, S. Hasenauer, K. Scipal, H. Bonekamp, J. Figa, and C. Anderson, "Initial soil moisture retrievals from the METOP-a advanced scatterometer (ASCAT)," Geophysical Research Letters, vol. 34, no. 20, oct 2007.

[22] W. Wagner, J. Noll, M. Borgeaud, and H. Rott, "Monitoring soil moisture over the canadian prairies with the ERS scatterometer," IEEE Transactions on Geoscience and Remote Sensing, vol. 37, no. 1, pp. 206-216, 1999.

[23] V. Naeimi, K. Scipal, Z. Bartalis, S. Hasenauer, and W. Wagner, "An Improved Soil Moisture Retrieval Algorithm for ERS and METOP Scatterometer Observations," IEEE Transactions on Geoscience and Remote Sensing, vol. 47, no. 7, pp. 1999-2013, jul 2009.

[24] W. Wagner, G. Lemoine, M. Borgeaud, and H. Rott, "A study of vegetation cover effects on ERS scatterometer data," IEEE Transactions on Geoscience and Remote Sensing, vol. 37, no. 2, pp. 938-948, mar 1999.

[25] D. J. Leroux, Y. H. Kerr, A. A. Bitar, R. Bindlish, T. J. Jackson, B. Berthelot, and G. Portet, "Comparison between SMOS, VUA, ASCAT, and ECMWF soil moisture products over four watersheds in u.s." IEEE Transactions on Geoscience and Remote Sensing, vol. 52, no. 3, pp. 1562-1571, mar 2014.

[26] W. Wagner, L. Brocca, V. Naeimi, R. Reichle, C. Draper, R. de Jeu, D. Ryu, C.-H. Su, A. Western, J.-C. Calvet, Y. H. Kerr, D. J. Leroux, M. Drusch, T. J. Jackson, S. Hahn, W. Dorigo, and C. Paulik, "Clarifications on the "Comparison Between SMOS, VUA, ASCAT, and ECMWF Soil Moisture Products Over Four Watersheds in U.S."," IEEE Transactions on Geoscience and Remote Sensing, pp. 1-6, 2013.

[27] I. Pfeil, M. Vreugdenhil, S. Hahn, W. Wagner, P. Strauss, and G. Blöschl, "Improving the seasonal representation of ASCAT soil moisture and vegetation dynamics in a temperate climate," Remote Sensing, vol. 10 , no. 11 , p. 1788 , nov 2018 .

[28] M. Rodell, P. R. Houser, U. Jambor, J. Gottschalck, K. Mitchell, C.-J. Meng, K. Arsenault, B. Cosgrove, J. Radakovich, M. Bosilovich, J. K. Entin*, J. P. Walker, D. Lohmann, and D. Toll, "The Global Land Data Assimilation System," Bulletin of the American Meteorological Society, vol. 85, pp. 381-394, Mar. 2004.

[29] W. Dorigo, W. Wagner, C. Albergel, F. Albrecht, G. Balsamo, L. Brocca, D. Chung, M. Ertl, M. Forkel, A. Gruber, E. Haas, P. D. Hamer, M. Hirschi, J. Ikonen, R. de Jeu, R. Kidd, W. Lahoz, Y. Y. Liu, D. Miralles, T. Mistelbauer, N. Nicolai-Shaw, R. Parinussa, C. Pratola, C. Reimer, R. van der Schalie, S. I. Seneviratne, T. Smolander, and P. Lecomte, "ESA CCI Soil Moisture for improved Earth system understanding: State-of-the art and future directions," Remote Sensing of Environment, vol. 203, pp. 185-215, Jul. 2017.

[30] A. Stoffelen, "Toward the true near-surface wind speed: Error modeling and calibration using triple collocation," Journal of Geophysical Research, vol. 103, no. C4, p. 7755, 1998.

[31] A. Gruber, C.-H. Su, S. Zwieback, W. Crow, W. Dorigo, and W. Wagner, "Recent advances in (soil moisture) triple collocation analysis," International Journal of Applied Earth Observation and Geoinformation, vol. 45, pp. 200-211, Mar. 2016.

[32] Z. Bartalis, K. Scipal, and W. Wagner, "Azimuthal anisotropy of scatterometer measurements over land," IEEE Transactions on Geoscience and Remote Sensing, vol. 44, no. 8, pp. 2083-2092, 2006.

[33] V. Naeimi, Z. Bartalis, and W. Wagner, "ASCAT Soil Moisture: An Assessment of the Data Quality and Consistency with the ERS Scatterometer Heritage," Journal of Hydrometeorology, vol. 10, no. 2, pp. 555-563, 2009

[34] S. Hahn, C. Reimer, M. Vreugdenhil, T. Melzer, and W. Wagner, "Dynamic characterization of the incidence angle dependence of backscatter using metop ASCAT," IEEE Journal of Selected Topics in Applied Earth Observations and Remote Sensing, vol. 10, no. 5, pp. 2348-2359, 5 2017.

[35] E. P. W. Attema and F. T. Ulaby, "Vegetation modeled as a water cloud," Radio Science, vol. 13, no. 2, pp. 357-364, Mar. 1978. 
[36] J. Figa-Saldana, J. J. W. Wilson, E. Attema, R. Gelsthorpe, M. R. Drinkwater, and A. Stoffelen, "The advanced scatterometer (ASCAT) on the meteorological operational (MetOp) platform: A follow on for European wind scatterometers," Canadian Journal of Remote Sensing, vol. 28, no. 3, pp. 404-412, 2002.

[37] R. V. Gelsthorpe, E. Schied, and J. J. W. Wilson, “ASCAT - Metop's advanced scatterometer," ESA Bulletin (ISSN 0376-4265), vol. 102, pp. 19-27, 2000.

[38] J. J. W. Wilson, C. Anderson, M. A. Baker, H. Bonekamp, J. F. Saldaña, R. G. Dyer, J. A. Lerch, G. Kayal, R. V. Gelsthorpe, M. A. Brown, E. Schied, S. Schutz-Munz, F. Rostan, E. W. Pritchard, N. G. Wright, D. King, and Ü. Onel, "Radiometric Calibration of the Advanced Wind Scatterometer Radar ASCAT Carried Onboard the METOP-A Satellite," IEEE Transactions on Geoscience and Remote Sensing, vol. 48, pp. 3236-3255, Aug. 2010.

[39] C. Anderson, J. Figa, H. Bonekamp, J. J. W. Wilson, J. Verspeek, A. Stoffelen, and M. Portabella, "Validation of Backscatter Measurements from the Advanced Scatterometer on MetOp-A," Journal of Atmospheric and Oceanic Technology, vol. 29, no. 1, pp. 77-88, Jan. 2012.

[40] P. Righetti and R. Dyer, "Feasibility of Metop-A Mission Extension on Drifting Local Time," in 26th International Symposium on Space Flight Dynamics (ISSFD), jun 2017.

[41] M. Rodell, P. R. Houser, A. A. Berg, and J. S. Famiglietti, "Evaluation of 10 methods for initializing a land surface model," Journal of Hydrometeorology, vol. 6, no. 2, pp. 146-155, apr 2005.

[42] H. Beaudoing and M. Rodell, "NASA/GSFC/HSL, GLDAS Noah Land Surface Model L4 3 hourly 0.25 x 0.25 degree V2.1, Greenbelt, Maryland, USA, Goddard Earth Sciences Data and Information Services Center (GES DISC)," 10.5067/E7TYRXPJKWOQ, 2016, accessed: 201803-20.

[43] A. Gruber, W. A. Dorigo, W. Crow, and W. Wagner, "Triple collocationbased merging of satellite soil moisture retrievals," IEEE Transactions on Geoscience and Remote Sensing, vol. 55, no. 12, pp. 6780-6792, dec 2017.

[44] A. Gruber, T. Scanlon, R. van der Schalie, W. Wagner, and W. Dorigo, "Evolution of the ESA CCI soil moisture climate data records and their underlying merging methodology," Earth System Science Data, vol. 11, no. 2, pp. 717-739, may 2019.

[45] ESA CCI Soil Moisture, Algorithm Theoretial Baseline Document (ATBD) D2.1 Version 04.5, 2019.

[46] R. van der Schalie, R. de Jeu, Y. Kerr, J. Wigneron, N. RodríguezFernández, A. Al-Yaari, R. Parinussa, S. Mecklenburg, and M. Drusch, "The merging of radiative transfer based surface soil moisture data from SMOS and AMSR-e," Remote Sensing of Environment, vol. 189, pp. 180-193, feb 2017.

[47] C. D. M. Hansen, "Measures vegetation continuous fields (vcf) yearly global 0.05 deg," 2018.

[48] M. C. Peel, B. L. Finlayson, and T. A. McMahon, "Updated world map of the Köppen-Geiger climate classification," Hydrology and Earth System Sciences, vol. 11, no. 5, pp. 1633-1644, Oct. 2007.

[49] ESA, "Land Cover CCI Product User Guide Version 2.4," CCI Land Cover, Tech. Rep., 2014.

[50] A. Al-Yaari, J.-P. Wigneron, A. Ducharne, Y. Kerr, W. Wagner, G. De Lannoy, R. Reichle, A. Al Bitar, W. Dorigo, P. Richaume, and A. Mialon, "Global-scale comparison of passive (SMOS) and active (ASCAT) satellite based microwave soil moisture retrievals with soil moisture simulations (MERRA-Land)," Remote Sensing of Environment, vol. 152, pp. 614-626, Sep. 2014.

[51] F. Fascetti, N. Pierdicca, L. Pulvirenti, R. Crapolicchio, and J. MuñozSabater, "A comparison of ASCAT and SMOS soil moisture retrievals over Europe and Northern Africa from 2010 to 2013," International Journal of Applied Earth Observation and Geoinformation, vol. 45, pp. 135-142, Mar. 2016.

[52] K. Miyaoka, A. Gruber, F. Ticconi, S. Hahn, W. Wagner, J. Figa-Saldana, and C. Anderson, "Triple collocation analysis of soil moisture from metop-a ASCAT and SMOS against JRA-55 and ERA-interim," IEEE Journal of Selected Topics in Applied Earth Observations and Remote Sensing, vol. 10, no. 5, pp. 2274-2284, may 2017.

[53] P.-W. Liu, J. Judge, R. D. DeRoo, A. W. England, T. Bongiovanni, and A. Luke, "Dominant backscattering mechanisms at L-band during dynamic soil moisture conditions for sandy soils," Remote Sensing of Environment, vol. 178, pp. 104-112, Jun. 2016.

[54] K. Morrison and W. Wagner, "Explaining anomalies in SAR and scatterometer soil moisture retrievals from dry soilswith subsurface scattering," IEEE Transactions on Geoscience and Remote Sensing, vol. 58, no. 3, pp. 2190-2197, mar 2020.
[55] E. Högström, A. Trofaier, I. Gouttevin, and A. Bartsch, "Assessing seasonal backscatter variations with respect to uncertainties in soil moisture retrieval in siberian tundra regions," Remote Sensing, vol. 6, no. 9, pp. 8718-8738, sep 2014.

[56] E. Hogstrom and A. Bartsch, "Impact of backscatter variations over water bodies on coarse-scale radar retrieved soil moisture and the potential of correcting with meteorological data," IEEE Transactions on Geoscience and Remote Sensing, vol. 55, no. 1, pp. 3-13, jan 2017.

[57] R. D. Koster, Z. Guo, R. Yang, P. A. Dirmeyer, K. Mitchell, and M. J. Puma, "On the Nature of Soil Moisture in Land Surface Models," Journal of Climate, vol. 22, no. 16, pp. 4322-4335, Aug. 2009.

[58] S. Schlaffer, M. Chini, D. Dettmering, and W. Wagner, "Mapping wetlands in zambia using seasonal backscatter signatures derived from ENVISAT ASAR time series," Remote Sensing, vol. 8, no. 5, p. 402, may 2016.

[59] F. M. Henderson and A. J. Lewis, "Radar detection of wetland ecosystems: a review," International Journal of Remote Sensing, vol. 29, no. 20, pp. 5809-5835, oct 2008.

[60] C. Albergel, P. de Rosnay, C. Gruhier, J. Muñoz-Sabater, S. Hasenauer, L. Isaksen, Y. Kerr, and W. Wagner, "Evaluation of remotely sensed and modelled soil moisture products using global ground-based in situ observations," Remote Sensing of Environment, vol. 118, pp. 215-226, Mar. 2012.

[61] S. C. Steele-Dunne, S. Hahn, W. Wagner, and M. Vreugdenhil, "Investigating vegetation water dynamics and drought using metop ASCAT over the north american grasslands," Remote Sensing of Environment, vol. 224, pp. 219-235, apr 2019.

[62] S. Hahn, S. Elefante, T. Melzer, and W. Wagner, "Metop ASCAT Soil Moisture: Challenges, Products, Applications," in EUMETSAT Meteorological Satellite Conference, Rome, Italy, oct 2017.

[63] R. Quast and W. Wagner, "Analytical solution for first-order scattering in bistatic radiative transfer interaction problems of layered media," Applied Optics, vol. 55, no. 20, p. 5379, jul 2016.

[64] R. Quast, C. Albergel, J.-C. Calvet, and W. Wagner, "A generic firstorder radiative transfer modelling approach for the inversion of soil and vegetation parameters from scatterometer observations," Remote Sensing, vol. 11, no. 3, p. 285, feb 2019.

[65] A. Stoffelen, S. Aaboe, J.-C. Calvet, J. Cotton, G. D. Chiara, J. F.-S. na, A. A. Mouche, M. Portabella, K. Scipal, and W. Wagner, "Scientific developments and the EPS-SG scatterometer," IEEE Journal of Selected Topics in Applied Earth Observations and Remote Sensing, vol. 10, no. 5, pp. 2086-2097, may 2017.

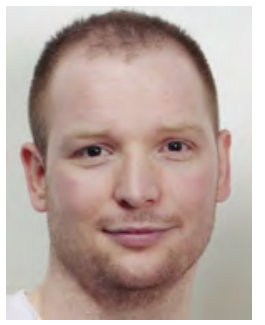

Sebastian Hahn received the B.Sc. degree in geodesy and geomatic engineering (2009) and the M.Sc. degree in geodesy and geophysics (2011) from Vienna University of Technology (TU Wien). He is currently working on his Ph.D. in microwave remote sensing at $\mathrm{TU}$ Wien. $\mathrm{He}$ is one of the key developers for the software package WARP (Soil Water Retrieval Package), which represents the implementation of the TU Wien soil moisture retrieval algorithm. He is focused on software development, multiprocessing, model calibration, and algorithmic improvements, which is in light of his Ph.D. studies. His main research interests include microwave remote sensing over land using active instruments, soil moisture retrieval algorithms and geophysical validation. 


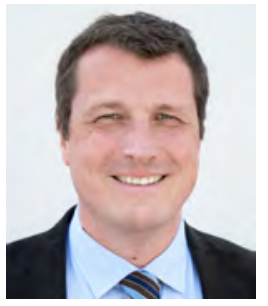

Wolfgang Wagner (M'98-SM'07) was borne in Austria in 1969. He received the Dipl.-Ing. degree in physics and the Dr.techn. degree in remote sensing from the Vienna University of Technology (TU Wien), Austria, in 1995 and 1999 respectively. In support of his master and $\mathrm{PhD}$ studies he received fellowships to carry out research at the University of Bern, Atmospheric Environment Service Canada, NASA, ESA, and the EC Joint Research Centre. From 1999 to 2001 he was with DLR. In 2001 he was appointed professor for remote sensing at TU Wien. Since 2012 he has been head of the Department of Geodesy and Geoinformation of TU Wien. He is co-founder and head of science of the EODC Earth Observation Data Centre. His main research interest is to gain physical understanding of the mechanisms driving the interaction of electromagnetic waves with the land surface. Based on this understanding he has developed models for retrieving soil moisture, biomass, and other land surface variables from scatterometer, SAR and full-waveform lidar observations. He is member of the EUMETSAT/ESA Science Advisory Group for Metop-SG SCA, and since 2016 chair of the GCOS/WCRP Terrestrial Observation Panel for Climate. From 2008 to 2012 he served as ISPRS Commission VII President and from 2009-2011 as editor-in-chief of the Open Access Journal "Remote Sensing". He is a recipient of the ISPRS Frederick J. Doyle Award for his scientific contributions in active remote sensing.

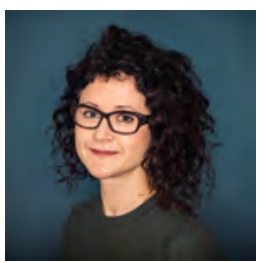

Susan C. Steele-Dunne received the S.M. and Ph.D. degrees in hydrology from the Massachusetts Institute of Technology, Cambridge, MA, USA, in 2002 and 2006, respectively. She has been with the Faculty of Civil Engineering and Geosciences at Delft University of Technology, in the Netherlands since 2008. Prof. Steele-Dunne leads the M-WAVE group, who perform research from field to global scales, combining in-situ and spaceborne sensors to improve our understanding of microwave interactions with vegetation. Her research interests include the the use of data assimilation, modeling and machine learning to exploit spaceborne radar instruments for applications in ecosystem and agricultural monitoring.

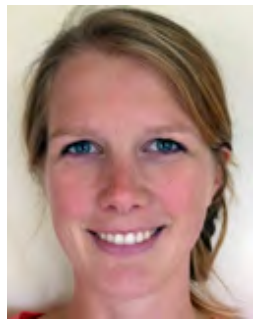

Mariette Vreugdenhil received the B.Sc. and M.Sc. degree in earth sciences with an emphasis on remote sensing from Vrije Universiteit Amsterdam, Amsterdam, The Netherlands, in 2009 and 2011, respectively. She obtained a $\mathrm{Ph} . \mathrm{D}$. in remote sensing with the Centre for Water Resource Systems and Department of Geodesy and Geoinformation, TU Wien, Vienna, Austria in 2016. Currently, she works as a senior scientist at the Department of Geodesy and Geoinformation at TU Wien. Her research interests are the development of retrieval algorithms for vegetation and soil moisture from active microwave observations, in particular from the Advanced SCATterometer on-board of EUMETSAT Metop satellites and from the Synthetic Aperture Radars on-board of the Copernicus Sentinel-1 satellites.

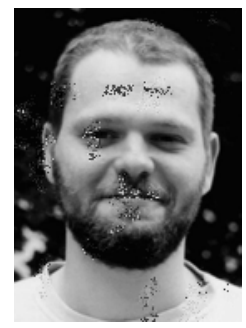

Thomas Melzer received the M.Sc. and Ph.D. degrees in computer science from the Vienna University of Technology (TU Wien), Vienna, Austria, in 1997 and 2002, respectively. He is currently with the Institute of Photogrammetry and Remote Sensing (IPF), TU Wien. His research interests include statistical pattern recognition, object reconstruction from 3-D point clouds, and analysis of scatterometer data. 